Article

\title{
Dual Search Maximum Power Point (DSMPP) Algorithm Based on Mathematical Analysis under Shaded Conditions
}

\section{Shahrooz Hajighorbani ${ }^{1,2, *}$, Mohd Amran Mohd Radzi ${ }^{1,2}$, Mohd Zainal Abidin Ab Kadir ${ }^{1}$ and Suhaidi Shafie ${ }^{1}$}

1 Department of Electrical and Electronic Engineering, Faculty of Engineering, Universiti Putra Malaysia, 43400 Serdang, Selangor, Malaysia;

E-Mails: amranmr@upm.edu.my (M.A.M.R.); mzk@upm.edu.my (M.Z.A.A.K.); suhaidi@upm.edu.my (S.S.)

2 Centre for Advanced Power and Energy Research, Faculty of Engineering, University Putra Malaysia, 43400 UPM Serdang, Malaysia

* Author to whom correspondence should be addressed; E-Mail: shahrooz.kntu@yahoo.com; Tel.: +60-17-6875-292.

Academic Editor: Tapas Mallick

Received: 25 August 2015 / Accepted: 13 October 2015 / Published: 27 October 2015

\begin{abstract}
Photovoltaic (PV) systems represent a clean, renewable source of energy that has non-linear current-voltage $(I-V)$ and power-voltage $(P-V)$ characteristics. To increase the efficiency, a PV system must operate at the maximum power point (MPP) to produce the maximum available power. Under uniform conditions, there is only a single MPP in the $P-V$ curve of a PV system; however, determining the MPP is more complicated under partially shaded conditions (PSCs) because multiple peak power points exist. In recent years, various studies have been performed to obtain the highest peak power point under PSCs, which is referred to as the global maximum power point (GMPP). In this paper, a novel method based on mathematical analysis that reduces the search zone and simultaneously identifies the possible MPPs in the specified zone is proposed; this proposed method is called the dual search maximum power point (DSMPP) algorithm. To evaluate the effectiveness of the proposed method, simulation and hardware implementations are carried out. The results show that the search time of GMPP is significantly reduced and the GMPP is detected in the minimum amount of time with high accuracy and minimum oscillation in the power produced.
\end{abstract}


Keywords: boost converter; global maximum power point (GMPP); partially shaded condition (PSC); photovoltaic (PV); perturb and observation (P \& O); series-parallel configuration (SP)

\section{Introduction}

Fossil fuels are sources of non-renewable energy that are finite; as a result, the sources of fossil fuels will eventually become depleted, resulting in a high cost of fuel while also affecting the environment, particularly in terms of global warming. In contrast, there are certain types of renewable energy resources, such as solar and wind energy, that are continually resupplied and are virtually inexhaustible. Among renewable energy resources, energy from the sun is commercially viable because of its potential for high productivity and low emissions [1]. In photovoltaic (PV) systems, there are certain factors that can create power losses, such as current and voltage mismatch [2,3], the accumulation of dust on a PV module's surface [4], the angle of prevalence of such radiation, and the maximum power point (MPP) of a PV system.

PV systems are distinguished by their $I-V$ and $P-V$ characteristics, where $I, V$, and $P$ are the current, voltage, and power of the PV system, respectively. Each type of load connected to a PV system has a load line characteristic. The intersection point between the load line and $I-V$ characteristic of a PV system defines the operating point, which can be varied by changing the load value. Thus, the output power of a PV system, which is defined by multiplying the current by the voltage, ranges from nearly zero to the maximum value of the PV system. To solve this problem of variable power output and to simultaneously avoid further power losses, a maximum power point tracking (MPPT) algorithm is used to determine the maximum available power of a PV system. In recent years, many different MPPT algorithms [5-12] have been presented and can be classified into two general groups. The first group is conventional methods, such as perturb and observation (P \& O), incremental conductance (IC), and constant voltage (CV), and the second group is artificial intelligence methods, such as fuzzy logic (FL) [13-17], artificial neural network (ANN) [18-20], ant colony optimization [21], genetic algorithm (GA) [22], and particle swarm optimization (PSO) [23]. Among the conventional methods, $\mathrm{P} \& \mathrm{O}$ is the most frequently used because it is easy to implement in PV system controllers, but its major disadvantages are the long time required to reach the MPP and the high oscillations that occur when the MPP is obtained. On the other hand, artificial intelligence methods reduce oscillations and the time required to reach the MPP, but their implementation is more complex, they require more training data, and they have problems in specifying particles. Under uniform conditions, in which there is only a single peak power point, generally, all of the above-mentioned methods are successful in finding the MPP, and some of them have their own particular advantages, such as a short time required to obtain the MPP and acceptable oscillations. However, in some cases, e.g., under partially shaded conditions (PSCs), there are multiple power peaks; one of these peaks is the global maximum power point (GMPP), which has the highest power, and the other peaks are local maximum power points (LMPPs). To determine the GMPP, smart techniques should be combined with the above-mentioned methods. In recent years, many researchers have presented different strategies for finding the GMPP 
under shaded conditions. In [24], online current measurement and regular interrupts are used to address the partial shading issue. In [25], Levron et al. presented a sliding-mode controller based MPPT method which has faster convergence to MPP in comparison to PWM based MPPTs. In [26], a P \& O algorithm based on sliding-mode control of input inductor of a DC-DC converter is presented and this method is suitable when high power needs to be delivered to the grid. In [27], the particle swarm optimization (PSO) method is used to track the GMPP under shaded conditions. In [28], an artificial neural network based on the slope of power versus voltage is used to compensate for the ambiguity of solar irradiation conditions and the electrical characteristics of the load, as well as to avoid oscillation problems and the consequences of uncertain parameters. In [29], a hybrid system that combines the ANN and P \& O methods is used. In this paper, following a sudden change in power, an ANN is used to predict the classification of the optimal output voltage according to commensurate input irradiation conditions. Finally, by using the P \& O algorithm, the operating point moves to the GMPP. The PSO and $\mathrm{P} \& \mathrm{O}$ methods are used as a hybrid system in [30] to reduce the time required to find the GMPP. In this hybrid system, the $\mathrm{P} \& \mathrm{O}$ method is used to allot the nearest local maximum, and thereafter, the PSO is used to determine the GMPP. In [31], a two-stage method is presented; however, the problem with the two-stage method is the complexity of the system due to the requirement of two additional circuits (one for measuring the short-circuit current and the another one for measuring the open-circuit voltage). In another work [32], versatile reconfiguration is proposed, which requires many sensors and switches. In this method, the number of sensors and switches required increases with the number of rows. In [33], a two-stage method is also proposed to find the GMPP under partially shaded conditions. In the first stage, when the local MPP is found, the next search is started at the left and right sides of the first local MPP to find the GMPP. However, the drawback of this method is the low convergence speed in reaching the GMPP because it must search all possible MPPs. In [34], a new method based on the presence of photodiodes as irradiance sensors that serve as extra inputs to the algorithm is presented. In [35], fuzzy logic is used to adjust the duty cycle of the incremental conductance (IC) method, which reduces both oscillations and the time required to reach the GMPP. In [36], a variable step size can be implemented to overcome certain drawbacks, such as oscillations and the time required to reach the MPP $[37,38]$. The artificial intelligent methods are quite efficient, but each has its own drawbacks. For example, an ANN must provide enough experimental data to be trained. In the FL method, there are certain primary components, such as fuzzification and defuzzification that require large computational memory; in addition, the specific range of membership functions and rules should be varied according to the specific application. The PSO method is more useful in large PV systems with a large number of strings, but this method requires experience to set the parameters. In [39], a linear-function-based MPPT that is able to determine the GMPP under shaded conditions is presented; however, this method considers specific $P-V$ curves and is not successful in all partial shadowing scenarios. In some papers, the authors assume specific conditions for designing a new MPP algorithm and consider only specific $P-V$ and $I-V$ curves. For example, in some papers based on the PSO method, the authors define the initial particles to be near the local and global peaks, and they must change these particles for different $P-V$ curves. By considering all of the advantages and drawbacks of the abovementioned conditions for finding the GMPP, a new method based on mathematical analysis for reducing the search zone and consequently identifying the GMPP in the minimum amount of time is proposed. In this method, when partial shading occurs, the new 
reference voltage is calculated by a modified linear function that reduces the search zone, and then, the system begins to search for possible MPPs. Finally, when the potential location of the GMPP is recognized, the modified $\mathrm{P} \& \mathrm{O}$ method which is based on the adjusting duty cycle by step-size variation is implemented to obtain the GMPP. In this paper, Section 2 describes the PV system under study, followed by the model of the PV array under uniform conditions and PSCs for the series-parallel (SP) configuration. In Section 3, the principle of a boost converter is explained. In Section 4, the linear function method is explained, and in Section 5, the proposed MPPT algorithm is presented. In Section 6, the simulation results and the related analysis performed in MATLAB/Simulink are presented. The hardware setup is presented in Section 7. Finally, the last section summarizes the findings obtained by implementing the proposed method.

\section{Photovoltaic (PV) System Model}

\subsection{PV Array Model under Uniform Conditions}

The smallest unit of a PV module is the solar cells that are connected in series. The equivalent circuit of a solar cell is shown in Figure 1, where $R_{S}$ and $R_{S H}$ are the series and shunt resistances, respectively. The efficiency of a solar cell is quite sensitive to variations in the series resistance, but it is not as sensitive to variations in the shunt resistance. As a result, $R_{S H}$ can be assumed to be infinite; that is, the circuit is an open circuit. The current-voltage characteristics of a solar cell can be described by Equation (1):

$$
I=I_{P H}-I_{S}\left[\exp \left(\frac{q \times\left(V+\left(R_{S} \times I\right)\right)}{A \times K_{B} \times T}\right)-1\right]-\frac{V+\left(R_{S} \times I\right)}{R_{S H}}
$$

where $I$ and $V$ are the output current and voltage of the solar cell, respectively; $I_{P H}$ and $I_{S}$ are the photocurrent and saturation current, respectively; $K_{B}=1.38 \times 10^{-23} \mathrm{~J} / \mathrm{K}$ and $q=1.6 \times 10^{-19} \mathrm{C}$ are Boltzmann's constant and the elementary charge, respectively; $A$ is an ideality factor with a value between 1 and 2 .

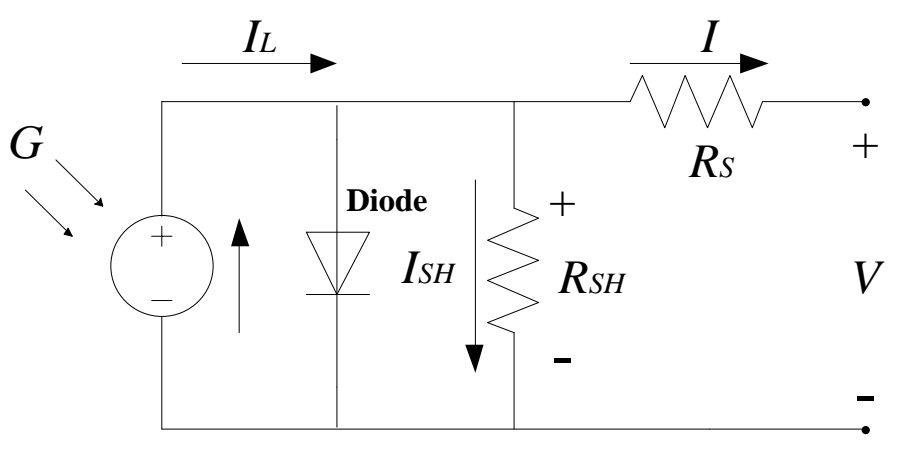

Figure 1. Equivalent circuit of a photovoltaic (PV) cell.

To produce higher current and voltage, modules are connected as a PV array in different configurations, for example, series-parallel (SP), total-cross-tied (TCT) and bridge-link (BL); each configuration has certain advantages and disadvantages [40]. In the SP configuration, which was selected for use in this work, the modules are connected in a series in a string to produce higher current; then, these strings are connected in parallel to produce higher voltage. When the modules in a 
string are connected in series, the current of the string is equal to the lowest value of the module's current. Thus, if any partial shading of the PV system occurs due to the presence of obstacles such as trees, birds, or clouds, the current of the module under reduced illumination is reduced and the generated power of the affected module is dissipated by the low-illumination conditions, thereby resulting in hot spot problems in the affected module. When modules are connected in series, the decreasing current in the module reduces the current of the string and consequently reduces the total power of the array. To solve these problems and to avoid the dissipation of power in PV modules, bypass diodes are connected in parallel to each module. When the module is shaded in a string, the module is short-circuited by forward biasing the related bypass diode. However, by installing these bypass diodes, multiple peak power points are created for the PV system. Among these peak powers, one point has the highest power, which is called the global maximum power point (GMPP), and the other points are local maximum power points (LMPPs). In addition to the bypass diode, to protect the effect of the resulting potential differences between the series-connected strings, a blocking diode is connected in series with each string.

\subsection{Mathematical Model of PV Array under Uniform and Partially Shaded Conditions}

In the series-parallel (SP) configuration, as shown in Figure 2, the modules are connected in series as strings, and then, multiple strings are connected in parallel. The voltage $V_{M}$ and current $I_{M}$ of a PV module formed by $N_{S} \times N_{P}$ solar cells are defined as follows:

$$
\begin{gathered}
I_{M}=N_{P} \times I, I_{S C M}=N_{P} \times I_{S C} \\
V_{O C M}=N_{S} \times V_{O C}, V_{M}=N_{S} \times V
\end{gathered}
$$

where $N_{S}$ is the number of cells connected in series and $N_{P}$ is the number of the cell's columns in a module connected in parallel. In both equations, the subscript $M$ denotes a module, and subscripts without $M$ denote an individual solar cell. As shown in Figure 2, if $N_{S M}$ presents the number of modules connected in a string and $N_{P M}$ represents the number of strings connected in parallel in a PV array, the output voltage and the current of the PV array under identical conditions can be defined as follows [41,42]:

$$
\begin{gathered}
I_{A}=N_{P M} \times I_{M}, I_{S C A}=N_{P M} \times I_{S C M} \\
V_{A}=N_{S M} \times V_{M}, V_{O C A}=N_{S M} \times V_{O C M} \\
R_{S A}=\frac{N_{S M}}{N_{P M}} R_{S M}
\end{gathered}
$$

where $R_{S M}$ and $R_{S A}$ are the total resistances of the PV module and the array, respectively. The output current of a PV array under uniform conditions can be derived as follows, whereas the subscripts $A$ and $M$ denote “Array" and "Module”, respectively:

$$
I_{A}=I_{\text {SCM }}-\frac{N_{\text {PM }} \times I_{\text {SCM }}}{\exp \left(\left(q \times V_{\text {ocM }}\right) /\left(N_{S} \times K_{B} \times T\right)\right)\left[\exp \left(q \times\left(V_{A}+\left(R_{\text {SA }} \times I_{A}\right)\right) /\left(A \times K_{B} \times T \times N_{S} \times N_{\text {SM }}\right)\right)-1\right]}
$$

By using Equation (7), the $I-V$ and $P-V$ characteristics of a PV array under uniform conditions is obtained. To analyze the behavior of the proposed MPP algorithm, the $I-V$ and $P-V$ curves of a PV 
array under PSCs are required. In [28], an approximate model of a PV array under PSCs for the SP configuration is presented. By referring back to Figure 2, $X$ denotes the string number and $N_{D X}$ denotes the number of shaded modules in the $X$ th string. Under uniform conditions, $N_{D X}$ is zero. In this model, one bypass diode is connected in parallel with each module, and the voltage drop across the bypass diode of shaded module is assumed to be zero. In addition, the PV array is composed of $N_{S M} \times N_{P M}$ modules. Under partially shaded conditions, the related equations can be expressed as follows:

$$
\begin{gathered}
I_{A}=\sum_{X=1}^{N_{P M}} I_{A X} \\
I_{S C A}=\sum_{X=1}^{N_{P M}} I_{S C A X} \\
V_{A X}=\left(N_{S M}-N_{D X}\right) V_{M} \\
V_{O C A X}=\left(N_{S M}-N_{D X}\right) V_{O C M} \\
R_{S A X}=\left(N_{S M}-N_{D X}\right) R_{S M}
\end{gathered}
$$

where $I_{A}$ and $I_{S C A}$ are the output current and the short-circuit current of the PV array under PSCs, respectively. $V_{A X}$ and $V_{O C A X}$ denote the output voltage and open-circuit voltage in the $X_{T H}$ string, respectively, and $R_{S A X}$ denotes the resistance in the Xth string.

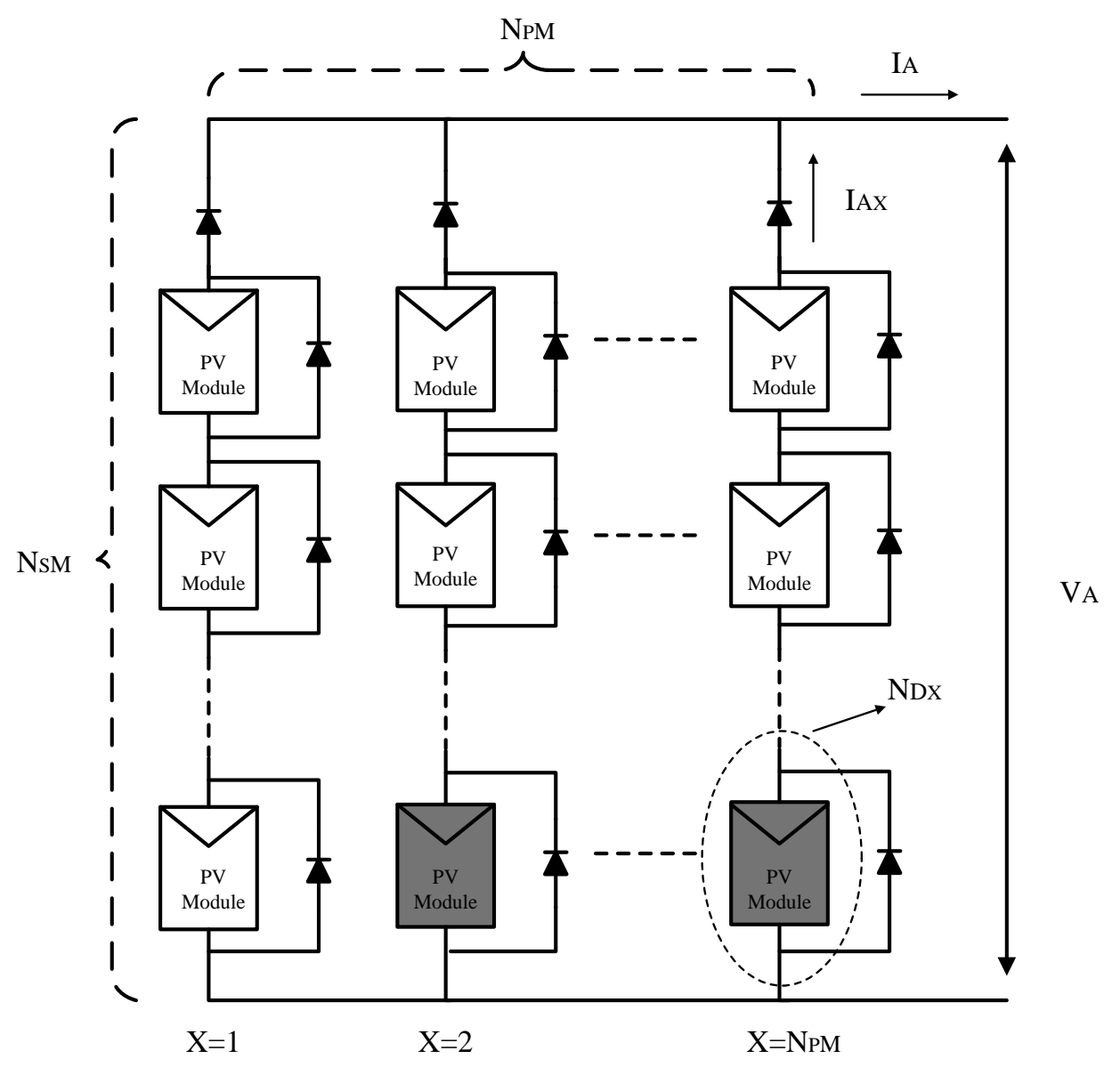

Figure 2. Series-parallel (SP) configuration of Photovoltaic (PV) array. 


\section{DC-DC Boost Converter}

The boost converter is a switch mode power supply that is used to increase the output voltage. As shown in Figure 3, the ideal topology of the boost converter is composed of an inductor, capacitor, switch and diode.

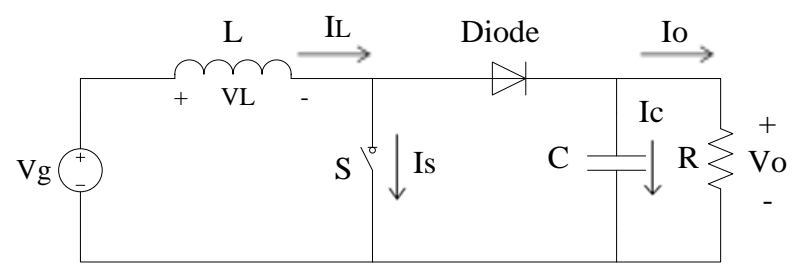

Figure 3. Topology of boost converter.

The voltage conversion ratio $M(D)$ can be defined as follow [43]:

$$
M(D)=\frac{V}{V_{g}}=\frac{1}{(1-D)}
$$

where $V$ and $V_{g}$ are the output and input voltages of the boost converter, respectively, and $D$ is the duty cycle, which is defined as the ratio of the turn-on duration to the switching time period $\left(T_{S}\right)$.

\section{Maximum Power Point Tracking (MPPT) Based on a Linear}

\section{Function under Partially Shaded Conditions (PSC)}

As explained in Section 2, there are different configurations for PV arrays, which are selected according to application. In this paper, the SP configuration is considered to investigate the behavior of the new MPPT algorithm under PSCs. Figure 4 shows the failure of the usual MPPT under PSCs for one scenario of shadowing; at the onset of the PSCs, the MPP drops as its voltage remains constant. Thus, the new MPP is located immediately below the MPP of uniform illumination, but as clearly shown, the new location is not the GMPP.

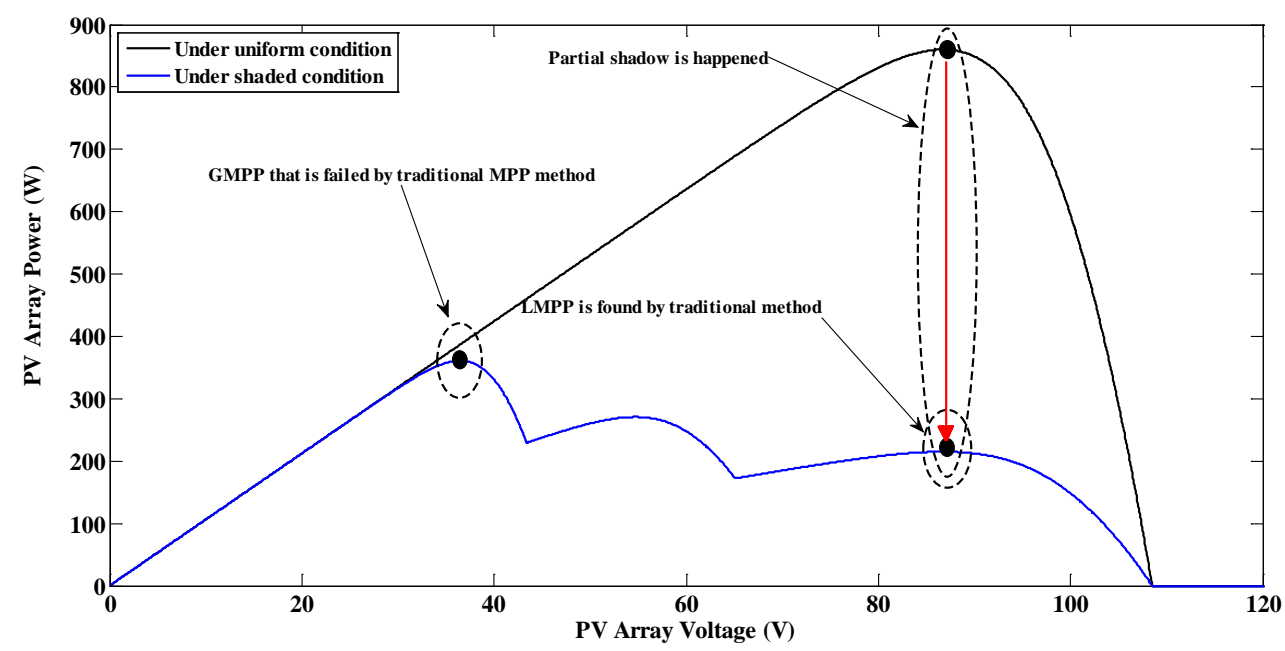

Figure 4. Failure of the maximum power point tracking (MPPT) algorithm to find the global maximum power point (GMPP). 
In [39], the linear function method, which is defined by Equation (14) [39] is used to find the GMPP by shifting the reference voltage to the new operating point, followed by using the incremental conductance (IC) method.

$$
V_{\text {refnew }}=\frac{V_{O C A}}{I_{S C A}} \times I_{P V}
$$

$V_{\text {refnew }}$ is the new reference voltage under PSCs; $V_{O C A}$ and $I_{S C A}$ are the open-circuit voltage and short-circuit current of the PV array, respectively; and $I_{P V}$ is the current of the PV array when the PS occurs.

The weakness of this work is that the presumed scenario is the only one in which the first MPPT obtained after transferring the operating point is considered as the GMPP. However, there are other shadow scenarios that contradict this assumption. In Figures 5 and 6 , the $I-V$ and $P-V$ curves for two different complicated shading scenarios are presented, which clearly show that the linear function method is not uniquely successful in finding the GMPP.

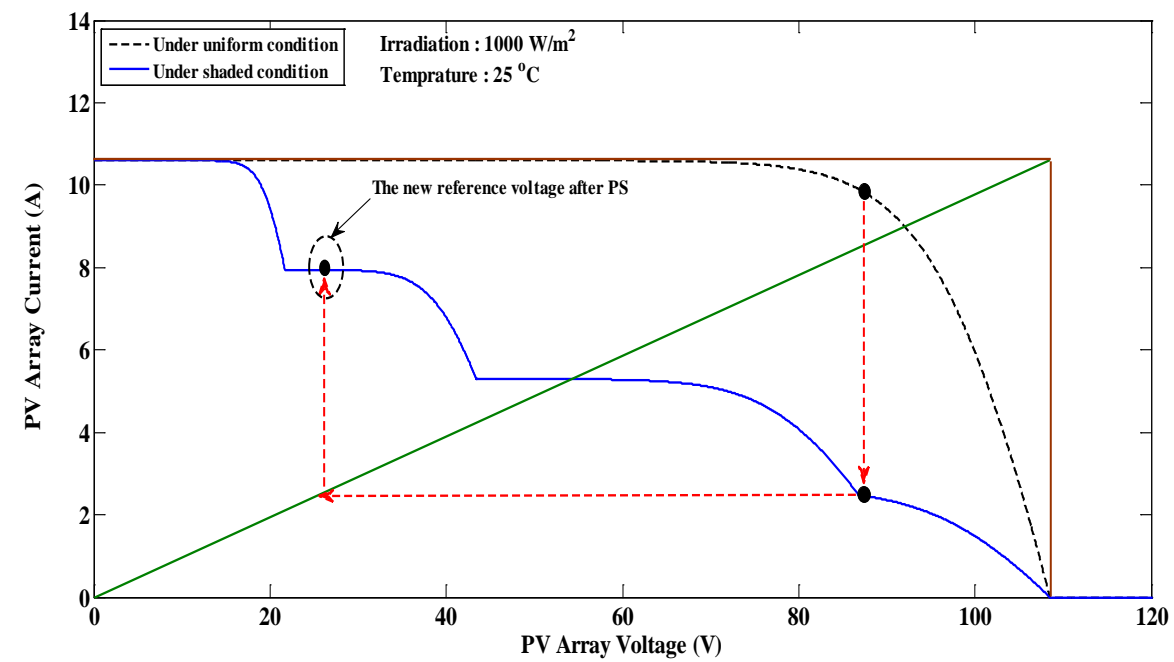

(a)

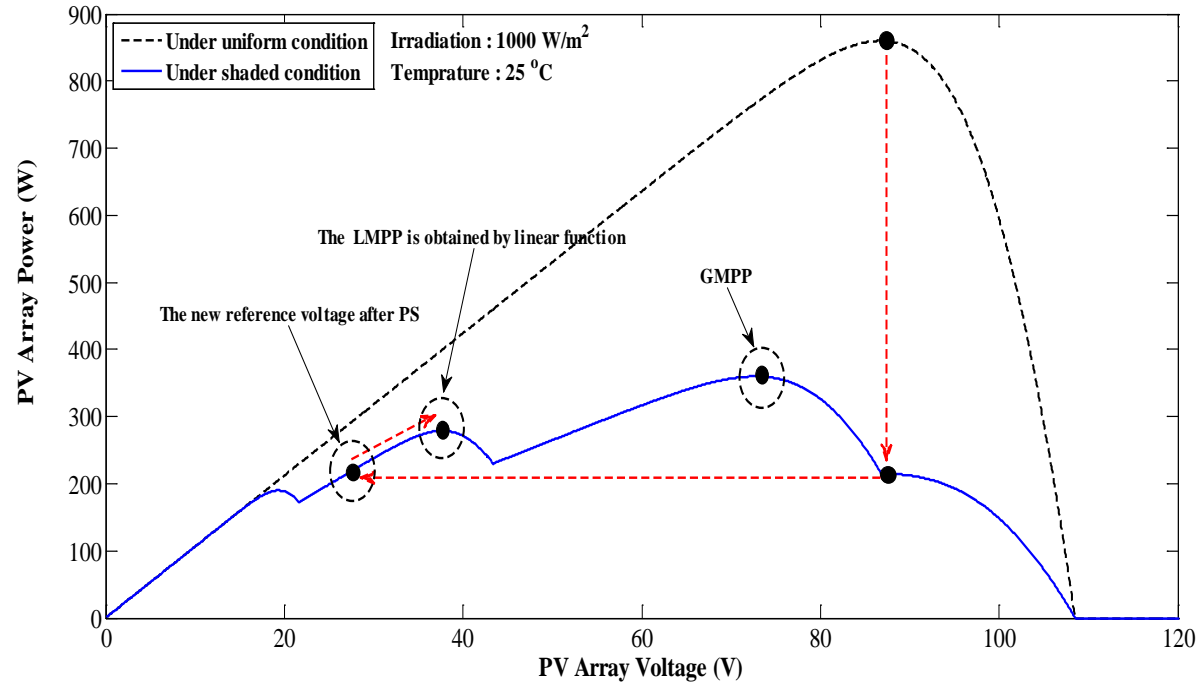

(b)

Figure 5. Tracking of the GMPP based on the linear function method for the first case of the complicated scenario (a) $I-V$ curve and (b) $P-V$ curve. 


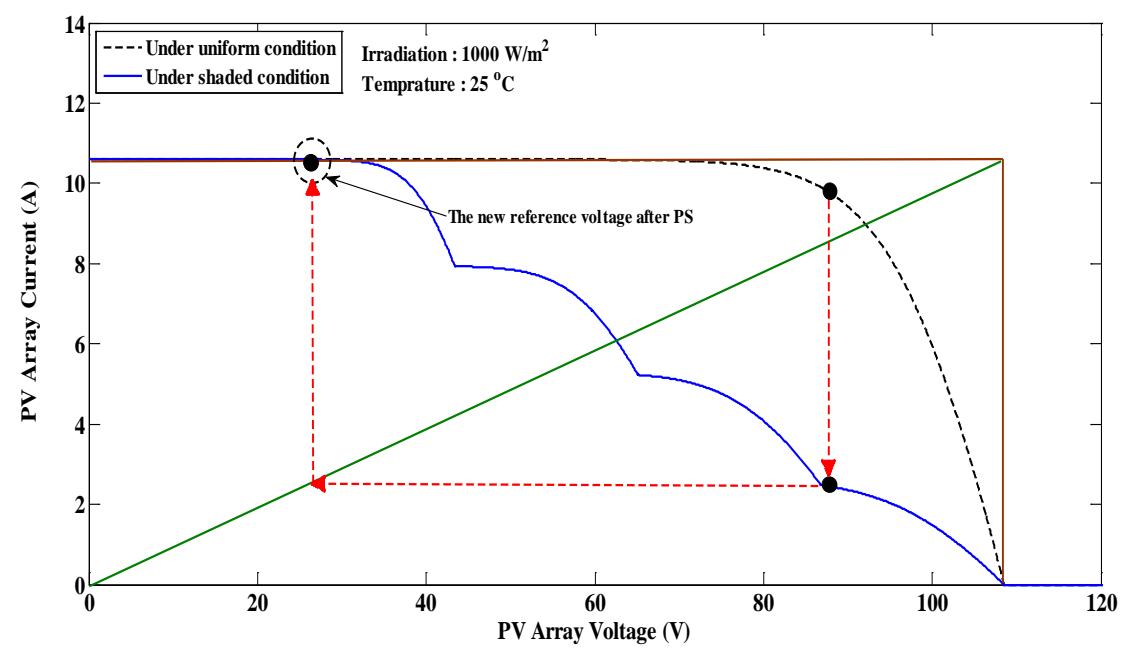

(a)

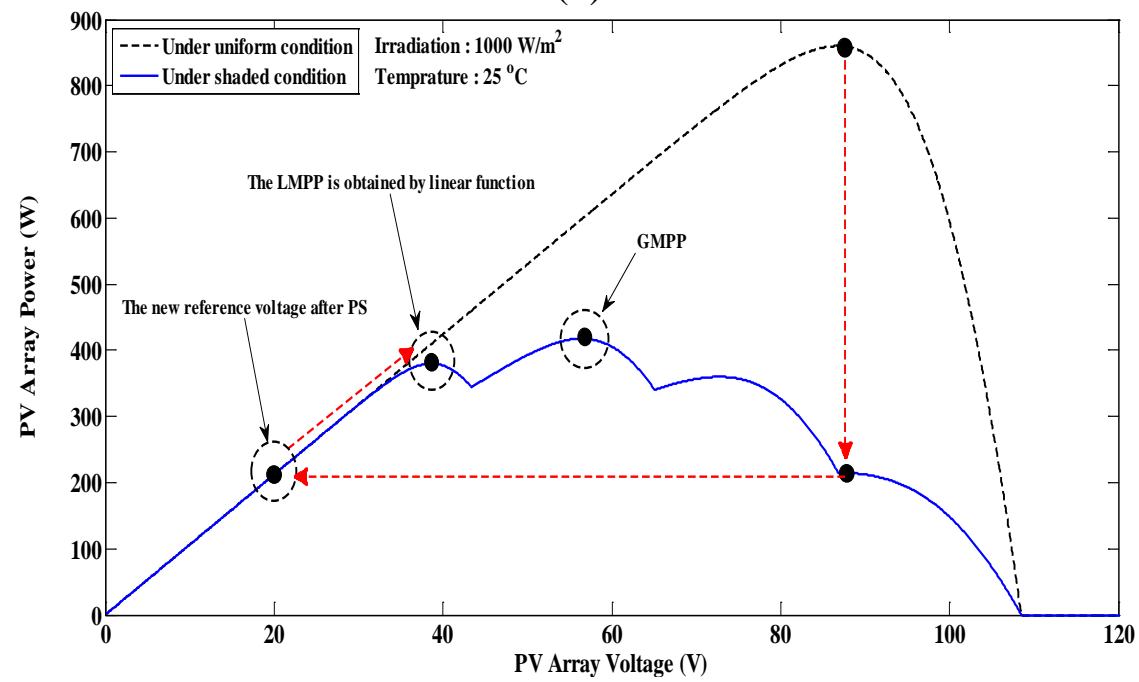

(b)

Figure 6. Tracking of the GMPP based on the linear function method for the second case of the complicated scenario (a) $I-V$ curve and (b) $P-V$ curve.

In this paper, a new hybrid method for determining the GMPP under shaded conditions is proposed, in which the search zone is determined by a modified linear function. In previous works, the approach required a search of all of the operating points from zero to the open-circuit voltage, which presents many problems, such as the need for additional circuits for measurements and additional switches. In the following, mathematical analysis, for the first time, is performed to prove that the GMPP is not on the left side of the new reference voltage.

In this analysis, two significant factors should be considered:

(1) The open-circuit voltage and short-circuit current methods are alternative techniques for obtaining the MPP. The open-circuit method is based on the relationship between the voltage of the PV array at the maximum power point $\left(V_{M P P}\right)$ and the open-circuit voltage of the PV array $\left(V_{O C A}\right)$. The short-circuit current method is based on the relationship between the current of the PV array at the MPP $\left(I_{M P P}\right)$ and the short-circuit current of the PV array $\left(I_{S C A}\right)$. In these methods, the voltage and current at the MPP are approximately $80 \%$ of the open-circuit voltage and $92 \%$ of the short-circuit current, respectively [44-46]. 
(2) In PSCs with multi-peak power points, the distance between peak powers are integral multiples of $80 \%$ of the open-circuit of the PV module $\left(n \times 0.8 \times V_{O C \_ \text {Module }}\right)$, where $n$ is an integer. If the minimum number of different levels of the shaded modules in the strings is one, then the minimum value of $n$ is one. In other words, the minimum distance between two consecutive peaks is $0.8 \times V_{O C \_M o d u l e}$.

To prove that the GMPP is not on the left side of the new reference voltage which is created by the linear function, general mathematical functions are obtained and then these obtained functions are considered for a PV array that consists of four strings and five modules per string to show the mathematical calculations. This proof is also applicable to the general PV array with $N_{P M} \times N_{S M}$ configuration. For this investigation, five general stages that cover different scenarios are considered, and the results are presented in Table 1 , where $n_{P S}$ is the number of strings that have shaded modules, $V_{\text {ref }}$ is the new reference voltage created under PSCs and calculated by Equation (14), $n_{M P P}$ is the number of peak powers in a related stage, and $K$ is the calculated integer value (the number of shaded modules in the string) where the maximum power peaks are on the left side of $V_{\text {ref. }}$

Table 1. Mathematical analysis from the results based on the linear function.

\begin{tabular}{|c|c|c|c|c|c|}
\hline $\begin{array}{r}\text { Stage } \\
\text { Parameter }\end{array}$ & 1 & 2 & 3 & 4 & 5 \\
\hline$n_{P S}$ & 1 & 2 & 2 & 3 & 3 \\
\hline$V_{\text {reff }}$ & $0.69 V_{O C A}$ & $0.46 V_{O C A}$ & $0.46 V_{O C A}$ & $0.23 V_{O C A}$ & $0.23 V_{O C A}$ \\
\hline$n_{M P P}$ & 2 & 2 & 3 & 2 & 4 \\
\hline$K$ & $1,2,3,4$ & 3,4 & 3,4 & 4 & 4 \\
\hline$I_{M P P \_1}$ & $0.69 I_{S C A}$ & $0.46 I_{S C A}$ & $0.46 I_{S C A}$ & $0.23 I_{S C A}$ & $0.23 I_{S C A}$ \\
\hline$V_{M P P \_1}$ & $0.8 V_{O C A}$ & $0.8 V_{O C A}$ & $0.8 V_{O C A}$ & $0.8 V_{O C A}$ & $0.8 V_{O C A}$ \\
\hline$P_{M P P \_1}$ & $0.552 V_{O C A} \times I_{S C A}$ & $0.368 V_{O C A} \times I_{S C A}$ & $0.368 V_{O C A} \times I_{S C A}$ & $0.184 V_{O C A} \times I_{S C A}$ & $0.184 V_{O C A} \times I_{S C A}$ \\
\hline$I_{M P P \_2}$ & $0.92 I_{S C A}$ & $0.92 I_{S C A}$ & $0.69 I_{S C A}$ & $0.92 I_{S C A}$ & $\sqrt{ }$ \\
\hline$V_{M P P \_2}$ & $0.48 V_{O C A}$ & $0.32 V_{O C A}$ & $0.32 V_{\text {OCA }}$ & $0.16 V_{O C A}$ & $\sqrt{ }$ \\
\hline$P_{M P P \_2}$ & $0.44 V_{O C A} \times I_{S C A}$ & $0.294 V_{O C A} \times I_{S C A}$ & $0.22 V_{O C A} \times I_{S C A}$ & $0.147 V_{O C A} \times I_{S C A}$ & $\sqrt{ }$ \\
\hline$I_{M P P \_3}$ & - & - & $0.92 I_{S C A}$ & - & $\sqrt{ }$ \\
\hline$V_{M P P \_3}$ & - & - & $0.16 V_{O C A}$ & - & $\sqrt{ }$ \\
\hline$P_{M P P \_3}$ & - & - & $0.147 V_{O C A} \times I_{S C A}$ & - & $\sqrt{ }$ \\
\hline$I_{M P P \_4}$ & - & - & - & - & $0.92 I_{S C A}$ \\
\hline$V_{M P P \_4}$ & - & - & - & - & $0.16 V_{O C A}$ \\
\hline$P_{M P P \_4}$ & - & - & - & - & $0.147 V_{O C A} \times I_{S C A}$ \\
\hline
\end{tabular}

In the first stage, only one string has shaded modules, and the other strings are not under a shadow; thus, two different voltage levels exist. The number of peaks under shaded conditions in the $P-V$ curve is equal to the number of different voltage levels that exist between strings; as a result, in this stage, two peak powers exist. As shown in Figures 5 and 6, when shadowing occurs, the MPP decreases while its corresponding voltage remains approximately $0.8 \times V_{O C A}$. The value of the current at this point is calculated as follow:

$$
I_{M P P_{-} P S}=\frac{\left(N_{P M}-n_{P S}\right)}{N_{P M}} \times 0.92 I_{S C A}
$$


where $n_{P S}$ is the number of strings that have shaded modules. The new reference voltage for obtaining the new operating point under PSCs should be calculated by Equation (14), for which $I_{P V}$ is determined by Equation (15), where it is equal to $I_{M P P-P S}$. Thus, this stage has only one string with shaded modules, and the reference voltage is acquired for $N_{P M}$ and $n_{P S}$ equal to 4 and 1 , respectively, by using Equations (14) and (15):

$$
V_{\text {ref }}=\frac{V_{O C A}}{I_{S C A}} \times I_{P V}=\frac{V_{O C A}}{I_{S C A}} \times \frac{3}{4} \times 0.92 I_{S C A}=0.69 V_{O C A}
$$

By increasing the number of shaded modules in the string, the second MPP is shifted by an integral multiple of $80 \%$ of the open-circuit of the PV module as follows:

$$
\begin{aligned}
& V_{M P_{-} 2}=\left(0.8 V_{O C A}-\frac{K}{N_{S M}} \times 0.8 V_{O C A}\right) \\
& \left(0.8 V_{O C A}-\frac{K}{N_{S M}} \times 0.8 V_{O C A}\right)<\frac{V_{O C A}}{I_{S C A}} \times I_{P V}
\end{aligned}
$$

where $K$ as it is mentioned is considered to be the number of shaded modules in the string for different scenarios of shadowing that shift the location of the possible MPP (which may have different integer values). The MPP is located on the left side of the new reference voltage if Equation (16) is more than Equation (17); thus, by solving Equation (18), the integer values for $K$ are determined. The obtained values of $K$ have their own specific values of $I_{M P P}$; therefore, the analysis should begin by evaluating the possibility that the GMPP is located on the left side of the new reference voltage. Figure 7 shows the different zones for the voltage of the PV array in the $P-V$ and $I-V$ curves, where the MPP can be located in the zones according to the scenarios.

For the first stage, in which only one string has shaded modules, the lowest value of $K$ is obtained to be 1 by solving Equation (18); consequently, $V_{M P P_{-} 2}$ will be $0.64 V_{O C A}$. The calculated values for $V_{\text {ref }}$ and $V_{M P P_{2} 2}$ are in the same zone (D), as shown in Figure 7, and thus, the second value of $K$ must be 2 . By substituting 2 for $K$ in Equation (17), $V_{M P P_{2} 2}$ will be $0.48 V_{O C A}$, and the corresponding value of $I_{M P P_{-} 2}$ is $0.92 I_{S C A}$. The maximum power values for the two power peaks in this stage are obtained as follows:

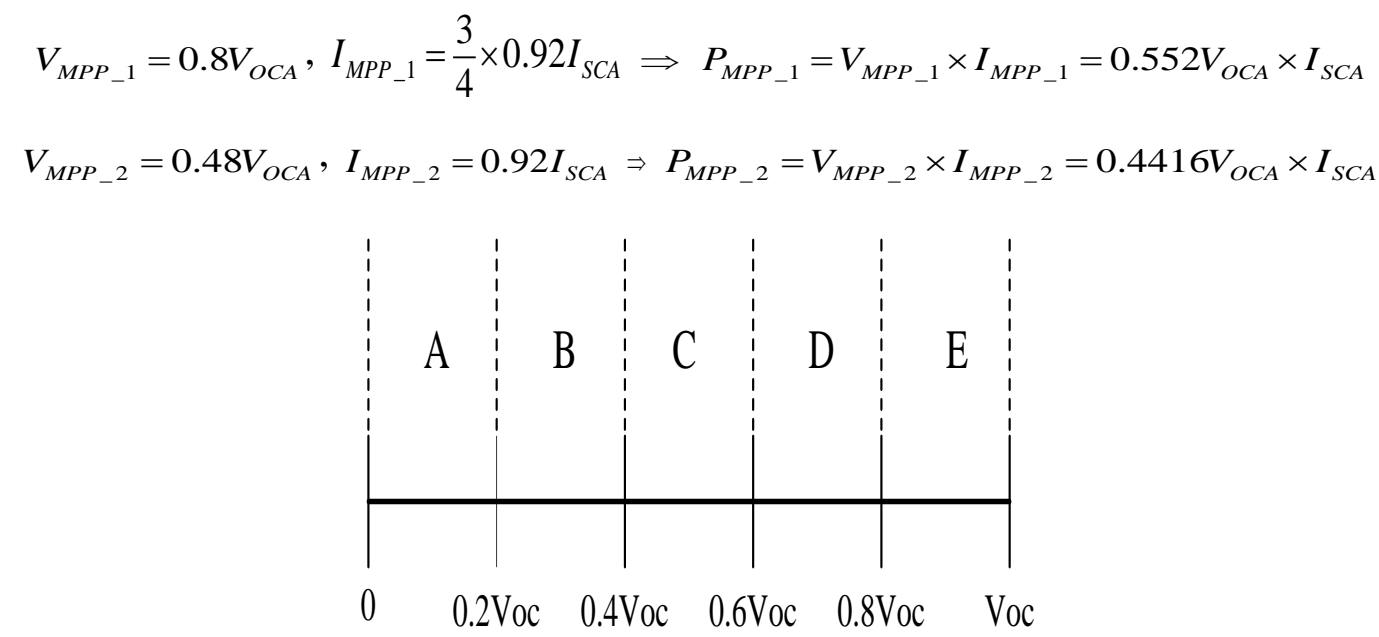

Figure 7. Zones for the possible MPPs. 
The maximum power for the second MPP is observed to be lower than the value for the first one. From Equation (17), $V_{M P P_{-} 2}$ is determined to decrease with increasing $K$ and is located in zones A, B and C; consequently, $P_{M P P_{-} 2}$ is reduced. This analysis demonstrates that all MPPs on the left side of the reference voltage are not the GMPP.

In the second stage, two strings are under a shadow and the number of shaded modules in the strings is assumed to be same; as a result, two different voltage levels exist, which results in two MPPs. The reference voltage is determined to be $0.46 V_{O C A}$, which is calculated using Equation (14). By solving Equation (18), the values obtained for $K$ to locate the MPP on the left side of the reference voltage are 3 and 4. In Table 1, the current, voltage and power values of the second MPP for $K$ equal to 3 are shown, and the power for the second MPP is less than that of the first MPP. Additionally, according to Equation (17), the voltage of the second MPP for $K$ equal to 4 is reduced; consequently, the corresponding power is also reduced. This finding proves that the MPPs on the left side of the reference voltage are not the GMPP.

In the third stage, the PV array has two strings with shaded modules, but the numbers of shaded modules in the two strings are not equal. In this case, there are three different levels of voltage that create three peak powers. By solving Equation (18), the integer values of $K$ for locating the MPP on the left side of reference voltage are obtained, as presented in Table 1 . For $K$ is equal to 3, the corresponding voltage of MPP is $0.32 V_{O C A}$, which is in zone $\mathrm{B}$, and the corresponding maximum power is $0.22 V_{O C A} \times I_{S C A}$, which is lower than the first maximum power value in this stage. For $K$ is equal to 4 , the value of maximum power is $0.147 V_{O C A} \times I_{S C A}$, which is also lower than the two other peak powers. In the fourth and fifth stages, the PV array with three shaded strings is considered, in which, for the fourth stage, the numbers of shaded modules in the strings are equal, but in the fifth stage, they are not equal; as a result, the numbers of peak powers in the fourth and fifth stages are 2 and 4, respectively. By solving Equation (18) for these two stages, the MPPs are determined to be located on the left side of the reference voltage when $K$ is equal to 4 ; thus, as presented in Table 1 , the peak power value is less than the peak powers located on the right side of the reference voltage. In Table 1, the values for the MPPs located on the right side of the reference voltage are indicated by check marks and can adopt different values for various values of $K$. According to the results presented

in Table 1, the GMPP cannot be located on the left side of the reference voltage; consequently, the search zone is reduced, thereby minimizing the time required to obtain the GMPP.

\section{Proposed Dual Search MPPT Algorithm}

The proposed method is based on a dual search, in which the search zone is reduced from the left side of the $P-V$ curve and, simultaneously, the controller starts to scan the possible MPPs at the right side of the $P-V$ curve. In this case, the both side of the GMPP are considered at the same time by limiting the search zone and simultaneously scanning from right to left. During scanning, the possible MPPs are identified; finally, after detecting the exact location of the GMPP, the modified P \& O method is implemented to obtain the GMPP. In the P \& O method, the voltage of the PV is perturbed, and then, the obtained power is measured. When both voltage and power increase, the duty cycle must be adjusted to increase the voltage; however, if the voltage increases and the power decreases, then the voltage should be reduced. Similarly, when the voltage decreases and the power also decreases, then 
the duty cycle must be adjusted to increase the voltage; in addition, when the voltage decreases and the power increases, the voltage should be reduced to move the operating point to MPP. In this algorithm, a modified linear function is proposed; moreover, other important factors are incorporated to reduce the search time of the GMPP, as described further below. The modified linear function is as follows:

$$
V_{\text {ref_mod }}=\left(\frac{V_{O C A}}{I_{S C A}} \times I_{P V}\right)+\left(\alpha \times \frac{V_{O C A}}{N_{S M}}\right)
$$

where $V_{\text {ref_mod }}$ is the new operating point under PSCs. In this equation, the second term $\left(\alpha \times\left(\mathrm{V}_{\mathrm{OCA}} / \mathrm{N}_{\mathrm{SM}}\right)\right)$ has a significant effect in reducing the time required to achieve the MPP. Moreover, in Equation (19), the value of $\alpha$ should be adjusted carefully because an inappropriate value of $\alpha$ can lead to a shift in the new operating point to the wrong MPP zone and can miss the GMPP. As noted above, the minimum different level of the shaded modules in strings is one, thus the minimum value of $n$ is one. In other words, the minimum distance between two consecutive peaks is $0.8 \times V_{O C_{-} \text {Module. So, }}$ $\alpha$ should be adjusted to the value which avoids shifting the new reference voltage to the other peak powers. Thus, the maximum value for $\alpha$ is 0.8 and selecting the smaller value can lead to shift the reference voltage to wrong zone. For example, as shown in Figure 8, A or B is the location of the reference voltage that can shift to A1 and A2 or B1 by considering Equation (19), which leads to obtain the first MPPT in less time after transferring the operating point. In this work, according to investigations and analyses of $P-V$ curves under PSC, the value of $\alpha$ is chosen as 0.75 .

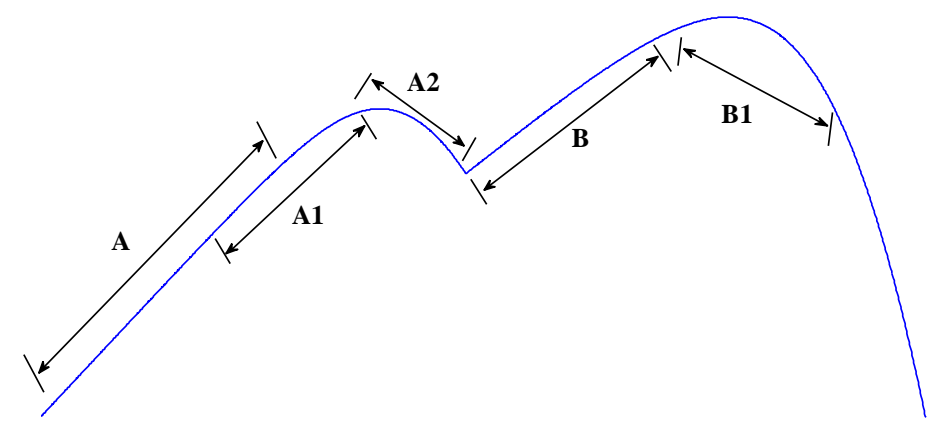

Figure 8. The possible location of new reference voltage.

By changing the climate conditions, both the short-circuit current and the open-circuit voltage in Equation (19) are updated by the following equations, where $G_{T}$ and $T_{C}$ are the irradiation and temperature under the new conditions, respectively $[47,48]$ :

$$
\begin{gathered}
I_{S C}=\frac{G_{T}}{G_{0}} I_{S C 0}\left[1+\lambda\left(T_{C}-T_{0}\right)\right] \\
V_{O C}=V_{O C 0}\left[1+\beta\left(G_{T 0}\right)\left(T_{C}-T_{0}\right)\right]\left[1+\delta\left(T_{C}\right) \ln \left(\frac{G_{T}}{G_{T 0}}\right)\right]
\end{gathered}
$$

where $\lambda$ and $\beta$ are the corrective coefficients of temperature for current and voltage, respectively, and $\delta$ is a corrective coefficient for solar irradiation. In Equations (20) and (21), the subscript zero indicates the standard reporting condition (SRC). In most studies, the temperature is assumed to be constant, which leads to the simplification of Equations (20) and (21).

The following are critical points to be considered based on the analysis and study of the $P-V$ curves of the PV array used in the proposed algorithm: 
1. Based on the above-described analyses, the GMPP is not on the left side of the new reference voltage created by the modified linear function.

2. In $P-V$ curves with multi-peak powers, when the GMPP is obtained, the magnitude of the subsequent MPPs decreases from either side.

3. The minimum distance between two consecutive MPPs is $0.8 \times V_{O C M}$.

4. When the duty cycle is the output of the P \& O method, the PID controller is not needed, and consequently, the controller will be simplified.

5. By carefully adjusting the step size of the duty cycle, the time required to reach the MPP and the overshoot and oscillations are significantly reduced, which can increase the efficiency of the system.

6. In the modified linear function, the open-circuit voltage and the short-circuit current of the PV array are the most important parameters that should be updated by changing the irradiation to obtain the correct value of the new reference voltage.

Figure 9 shows a flowchart of the proposed algorithm for finding the GMPP under uniform condition and PSCs. According to this algorithm, as shown in blocks 1 and 2 (B-1 and B-2), the voltage and current of the PV array at instants $k$ and $k-1$ are measured, and by using the modified P \& $\mathrm{O}$, the operating point is adjusted to the MPP. The difference in power between instants $k$ and $k-1$ are continuously calculated: if the difference is greater than a critical value $\left(\Delta P_{C r i t}\right)$, then partial shading occurs (B-4). The new reference voltage is calculated using the modified linear function, and the values of the power and voltage are stored (B-5). The existing operating point should be shifted to a new reference voltage (B-6), and thus, by considering the relation between the input and output voltages of a boost converter with a duty cycle, the controller should increase the duty cycle (B-7) to adjust the operating point to the neighbor of the new reference voltage. The value of $\varepsilon_{1}$ should be adjusted carefully because an inappropriate value can lead to miss the first MPPT after transferring the operating point $\left(P_{r e f}\right)$. The value of $\varepsilon_{1}$ is set to 0.4 to ensure the modified $\mathrm{P} \& \mathrm{O}$ is able to start, for obtaining the MPP at neighbor of the specified point, and if using the bigger value for $\varepsilon_{1}$ may lead possibility of finding another MPP. During the time when the operating point is conducted near the reference voltage, simultaneously, the controller should recognize and store the possible MPPs on the right side of the new reference voltage. As shown in Figure 10, at the right side of the possible MPP, $\mathrm{dp} / \mathrm{dv}$ is negative (B-8) and at the left side it is positive. When $\mathrm{dp} / \mathrm{dv}$ becomes positive (B-9), the second MPP under PSCs is obtained, and the related values of power and voltage are stored (B-11). At the onset of the PSCs, the MPP drops as its voltage remains nearly constant; thus, the first MPP under PSCs is located just below the MPP under uniform conditions. The parameter $j$ is used to count the number of possible MPPs obtained by scanning, and thus, when the first MPP is specified by scanning, $j$ will be equal to 1 (B-10). The scanning and storing of possible MPPs are continued until the existing operating point reaches the new reference voltage (B-6); then, by using the modified P \& O method, the power and voltage of the MPP at the new reference operating point are acquired and stored as $P_{\text {ref }}$ and $V_{\text {ref, }}$ respectively (B-13). In certain scenarios of shading, $P_{\text {ref }}$ is the same as the first MPP after shading ( $P_{a}$ ); thus, to determine whether $P_{r e f}$ is the same as $P_{a}$, the difference in voltage between these obtained points should be measured. If the difference is less than a predetermined value $\left(\varepsilon_{2}\right)(\mathrm{B}-14), P_{a}$ is the same point as $P_{\text {ref }}$ and $P_{\text {ref }}$ is the GMPP (B-15); otherwise, $P_{\text {ref }}$ should be compared with the last stored 
MPP during scanning (B-16). The value of $\varepsilon_{2}$ is considered 1 because at the start of the PSCs, it is possible for algorithm to store the voltage value $\left(V_{a}\right)$ during oscillation. According to the above-mentioned list of points to consider, if $P_{\text {ref }}$ is greater than the last stored value of power, $P_{\text {ref }}$ is the GMPP (B-17); otherwise, the duty cycle should be reduced (B-18) to ensure the next MPP can be reached (B-19); then, the values of power for $j$ and $j-1$ are compared to find the GMPP (B-23). The value of $j$ should be checked frequently to determine whether an operating point is the same as $P_{a}$ exists (B-25). If $j$ is equal to 1 , then the current MPP can be the first MPP after $P_{a}$ or the same as $P_{a}$. In the case where the difference between the voltage of the existing point for the MPP and $V_{a}$ is less than a predetermined value ( $\left.\varepsilon_{2}\right)$ (B-26), $P_{a}$ is the GMPP (B-27); otherwise, the MPPs of $P_{(j)}$ and $P_{a}$ for $j$ equals to 1 should be compared (B-28). If $P_{(j)}$ is greater than $P_{a}$, then $P_{(j)}$ is the GMPP (B-29); otherwise, $P_{a}$ is the GMPP (B-30).
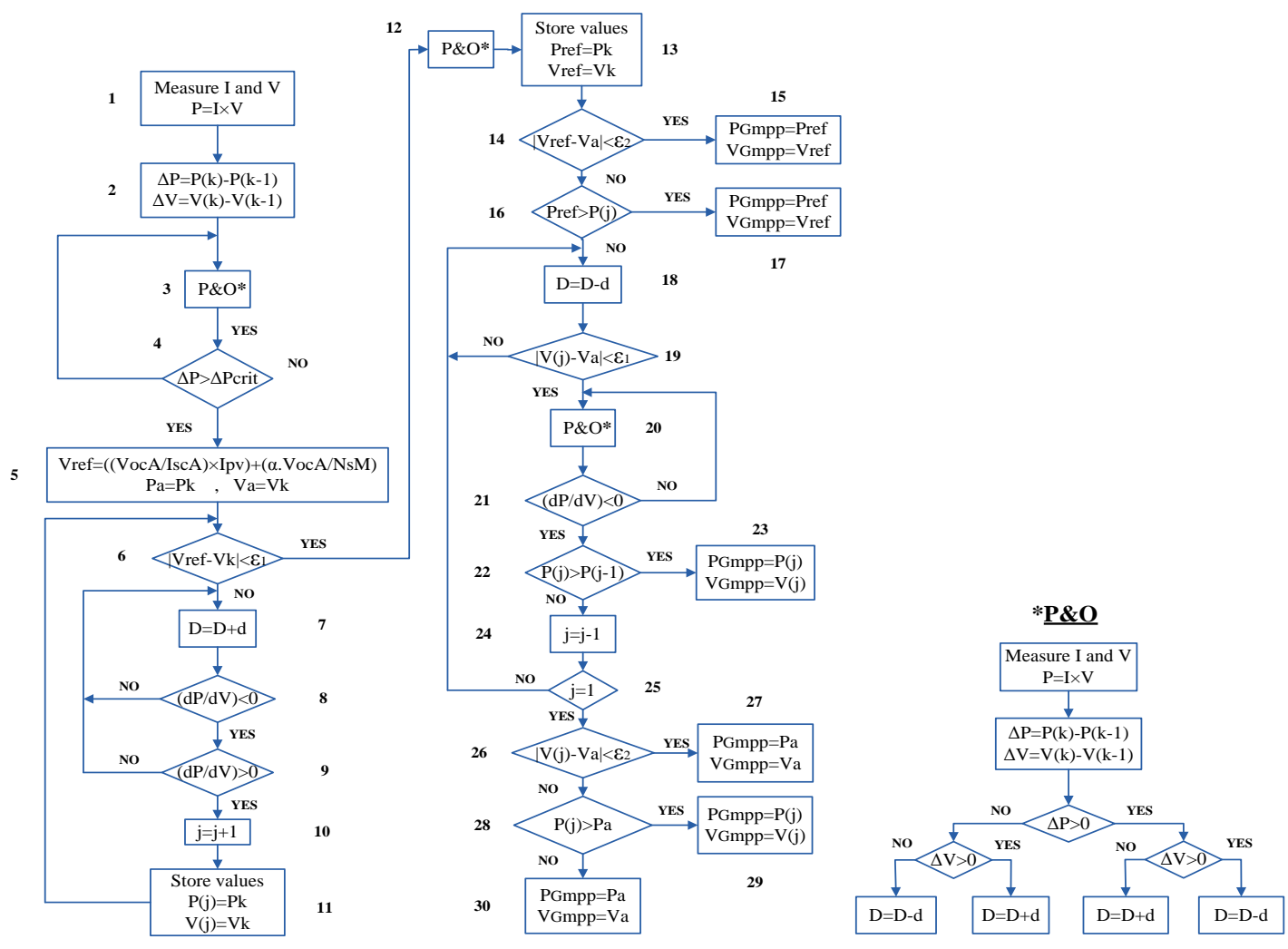

Figure 9. Flowchart of the proposed algorithm.

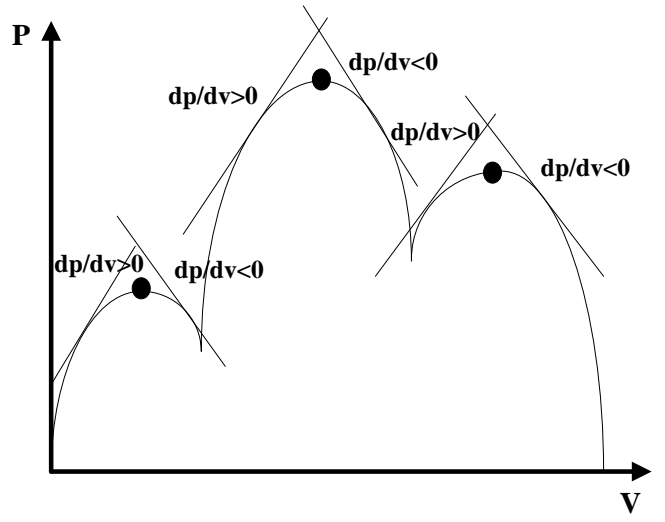

Figure 10. Change of $d p / d v$ in both sides of MPP. 
The P \& O method is used extensively because of its high tracking accuracy at the steady state, flexibility to adapt to rapidly changing atmospheric conditions, and simplicity in application. Despite these advantages, the P \& O method also has its drawbacks, such as a longer time to reach the MPP and the overshoot and oscillation of power around the MPP, which leads to a waste of some of the available energy. These drawbacks can be reduced by controlling the step size $d$ that is added or subtracted to the duty cycle $(D=D \pm d$ ). In this paper, by considering the following points, the $\mathrm{P} \& \mathrm{O}$ method is modified and the aforementioned drawbacks are reduced:

(A) When PSCs do not occur, according to Equation (13), the PV voltage should increase rapidly to reach the MPP, and thus, a greater value of $d$ is selected, which leads to a decrease in the time required to reach the MPP.

(B) When the MPP under uniform condition or the GMPP under PSCs is obtained, the value of $d$ should be adjusted to be lower so that the overshoot and oscillations can significantly be reduced.

(C) Under PSCs, a large value of $d$ should be selected to reach the operating point near the new reference voltage point, as calculated by Equation (19).

(D) When the existing operating point is near the new reference voltage, such as in blocks 6 and 19, a small value of $d$ should be selected to avoid missing the new operating point.

\section{Simulation Results}

In this work, simulation works are performed using MATLAB/Simulink to investigate the operation of the proposed DSMPP algorithm under PSCs. The considered PV array is based on KC40T PV modules connected in the SP configuration with four strings, and in each string, five modules are connected in series. The key specifications of the module are presented in Table 2, based on the manufacturer's data sheet. The DSMPP is implemented in the system as shown in Figure 11 which includes a PV array, a boost converter, an MPPT controller, and input filters. For the boost converter, the input capacitance is $1500 \mu \mathrm{F}$, the inductance is $200 \mu \mathrm{H}$, the output capacitance is $500 \mu \mathrm{F}$, and the load resistance is $50 \Omega$. The switching frequency of the system is $22 \mathrm{kHz}$. To evaluate the operation of the proposed algorithm, different complicated scenarios of shadowing are considered for simulation and practical parts in order to evaluate the operation of the DSMPP, which cover almost all of the shapes of the $P-V$ curve under PSCs.

Table 2. Specifications of Solar KC40T at $1000 \mathrm{~W} / \mathrm{m}^{2}$ and $25^{\circ} \mathrm{C}$.

\begin{tabular}{cc}
\hline Parameters & Values \\
\hline Power in maximum point, $M P P$ & $43 \mathrm{~W}$ \\
Voltage in maximum point, $V_{M P P}$ & $17.4 \mathrm{~V}$ \\
Current in maximum point, $I_{M P P}$ & $2.48 \mathrm{~A}$ \\
Open circuit voltage, $V_{O C}$ & $21.7 \mathrm{~V}$ \\
Short circuit current, $I_{S C}$ & $2.65 \mathrm{~A}$ \\
Temperature coefficient of $V_{O C}$ & $-0.0821 \mathrm{~V} /{ }^{\circ} \mathrm{C}$ \\
Temperature coefficient of $I_{S C}$ & $0.00106 \mathrm{~A} /{ }^{\circ} \mathrm{C}$ \\
Number of cells per module & 36 \\
\hline
\end{tabular}




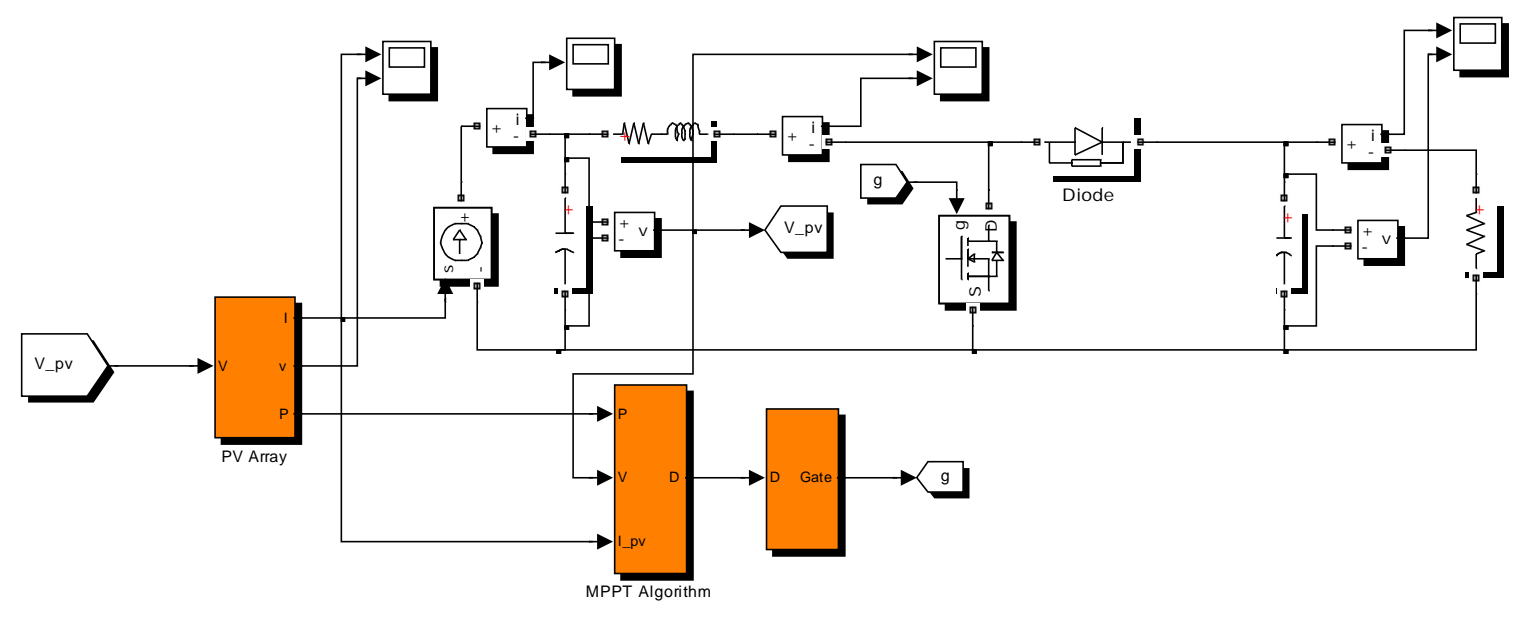

Figure 11. Configuration of system.

In order to investigate the behavior of the system, the scenarios of shadowing which are shown in Figure 12a,b are considered for the simulation part. Specifically, in Figure 12a, three strings have shaded modules, where the numbers of shaded modules in the strings are different. Meanwhile, in Figure 12b, three strings have shaded modules, but the numbers of shaded modules in two strings are the same; thus, there are three different levels of voltage, and consequently, three peak powers exist.

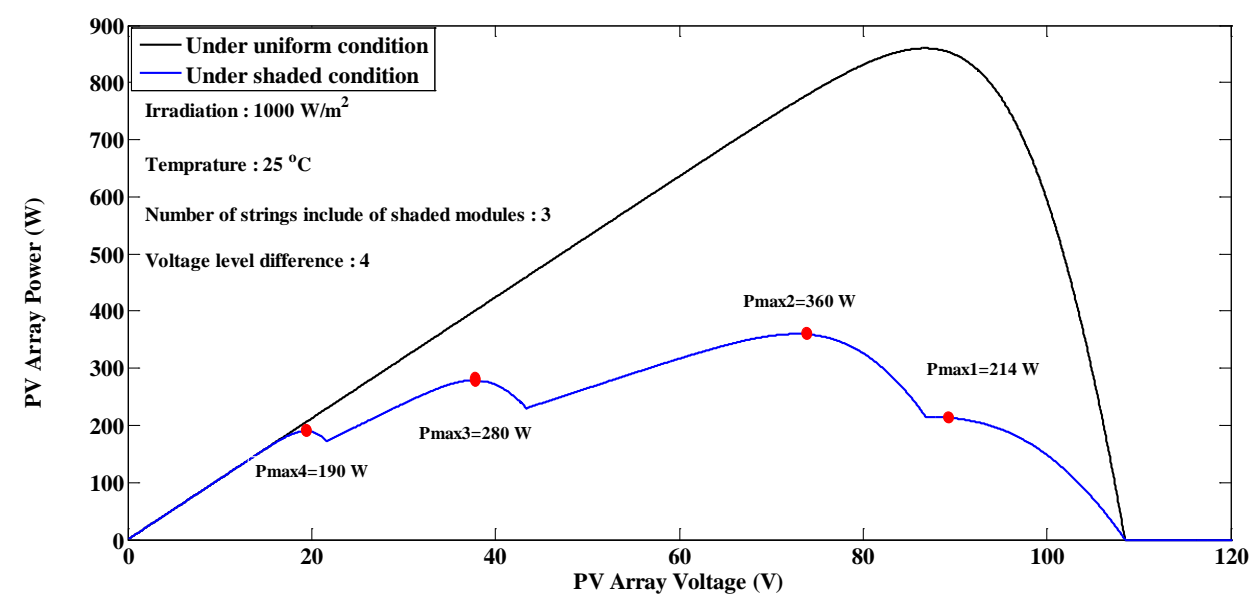

(a)

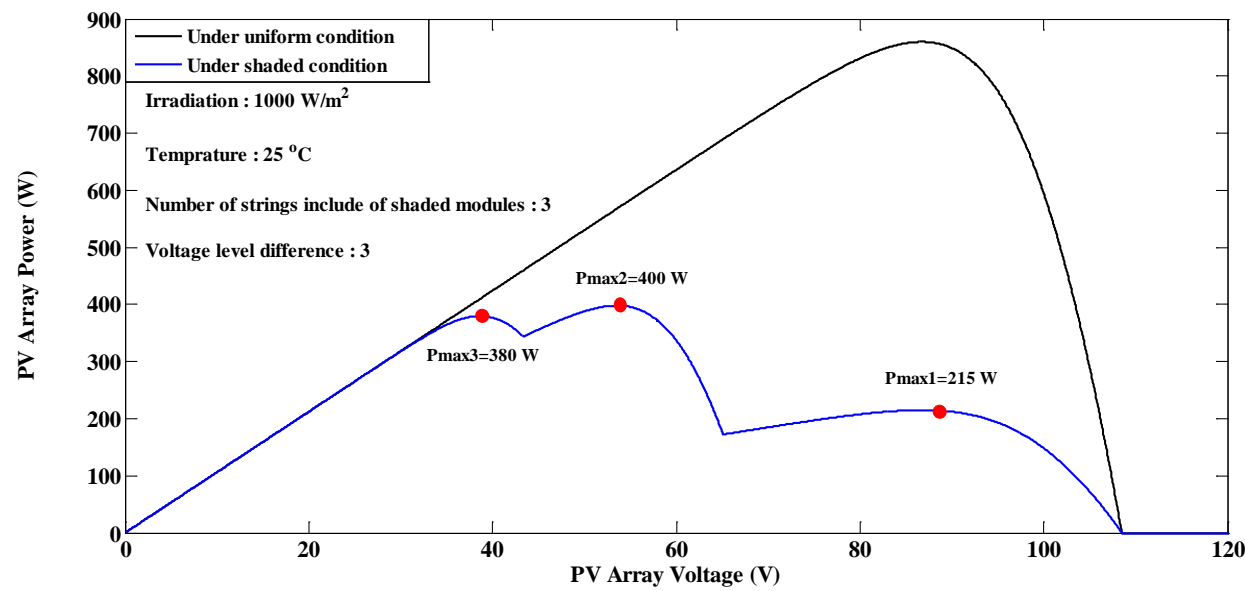

(b)

Figure 12. $P$ - $V$ curves for (a) first scenario of shadowing and (b) second scenario of shadowing. 
To further evaluate the performance of the proposed DSMPP method, the simulation for the scenarios depicted in Figure 12 have been done in MATLAB/Simulink, which involves three systems (S1, S2 and S3). In the first system (S1), the DSMPP method is implemented. In the second system (S2), the linear function method [39] is used. In the third system (S3), two-stage method [33] is used to find the GMPP under partially shaded conditions. The simulation results for the considered systems are summarized in Table 3 which has some abbreviations that are defined as follows:

SOP: Status of operation;

$\mathrm{T}_{\mathrm{GMPP}}$ : The global maximum power point reaching time (s);

$\mathrm{P}_{\text {ave_uni: }}$ The average maximum power point value in uniform condition $(\mathrm{W})$;

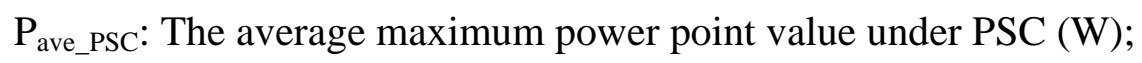

$\mathrm{P}_{\text {ripp_uni: }}$ The oscillation in power in uniform condition (W);

$\mathrm{P}_{\text {ripp_PSC: }}$ The oscillation in power under PSC (W).

In Figure 13, the simulation results for the scenario depicted in Figure 12a are shown. The calculated reference voltage is approximately $25 \mathrm{~V}$ and the related MPP is $280 \mathrm{~W}$. According to the linear function method [39] implemented in S2, under PSCs, the MPP with related to the new reference voltage should be the GMPP; however, as shown in Figure 13, S2 fails to find the GMPP, and a LMPP with a value of $280 \mathrm{~W}$ is detected. For S1 and S3, where DSMPP and two-stage methods are implemented respectively, the GMPP is obtained correctly. However, by comparing both, S1 can clearly find the GMPP in less time and the search time is significantly reduced. As shown in Table 3, $\mathrm{T}_{\mathrm{GMPP}}$ for S1 and S3 are 0.07 and 0.074 s respectively. Moreover, the oscillation in power decreases significantly for S1 which the oscillation values for S1 and S3 are 1 and $4 \mathrm{~W}$, respectively, when the GMPP is obtained ( $\left.\mathrm{P}_{\text {ripp_PSC}}\right)$. In comparing the proposed method (S1) with S2 and S3 in terms of oscillation in power in uniform condition $\left(\mathrm{P}_{\text {ripp_uni }}\right)$, $\mathrm{S} 1$ decreases the oscillation value significantly, and the values for S1, S2 and S3 are 0.3, 5 and $10 \mathrm{~W}$, respectively. In terms of overshoot, S1 does not have any overshoot, which may be largely attributed to implementation of the modified P \& O. By reducing the oscillation and overshoot while obtaining the GMPP, the system becomes more stable and the maximum available energy is reached.

Table 3. The simulation result for S1, S2 and S3.

\begin{tabular}{cccccccc}
\hline Items & \multirow{2}{*}{ Scenario } & SOP & T $_{\text {GMPP }}$ & $\mathbf{P}_{\text {ave_uni }}$ & $\mathbf{P}_{\text {ave_PSC }}$ & $\mathbf{P}_{\text {ripp_uni }}$ & P $_{\text {ripp_PsC }}$ \\
\hline S1 & 12a & Successful & 0.07 & 860 & 359.5 & 0.3 & 1 \\
S2 & $12 \mathrm{a}$ & Failed & - & 858 & - & 5 & - \\
S3 & $12 \mathrm{a}$ & Successful & 0.074 & 855 & 358 & 9 & 4 \\
S1 & $12 \mathrm{~b}$ & Successful & 0.0545 & 860 & 398 & 0.3 & 0.1 \\
S2 & $12 \mathrm{~b}$ & Failed & - & 858 & - & 5 & - \\
S3 & $12 \mathrm{~b}$ & Successful & 0.0563 & 855 & 397 & 9 & 1.5 \\
\hline
\end{tabular}

Next, the simulation results for the scenario depicted in Figure $12 \mathrm{~b}$ are shown in Figure 14 . Under PSCs, the new reference voltage is approximately $25 \mathrm{~V}$, and according to Figure 12b, the related MPP value is $380 \mathrm{~W}$. As shown in Figure 14, again, S2 fails to find the GMPP, and only a LMPP with a value of $380 \mathrm{~W}$ is obtained. However, by using S1 and S3, the GMPP is obtained. Between both, 
the time required to reach the GMPP $\left(\mathrm{T}_{\mathrm{GMPP}}\right)$ for $\mathrm{S} 1(0.0545 \mathrm{~s})$ is less than $\mathrm{S} 3(0.0565 \mathrm{~s})$. In addition, the oscillation in power ( $\mathrm{P}_{\text {ripp_PSG}}$ ) for S1 is also less than S3 when the GMPP is obtained, with the values of 0.1 and $1.5 \mathrm{~W}$, respectively.

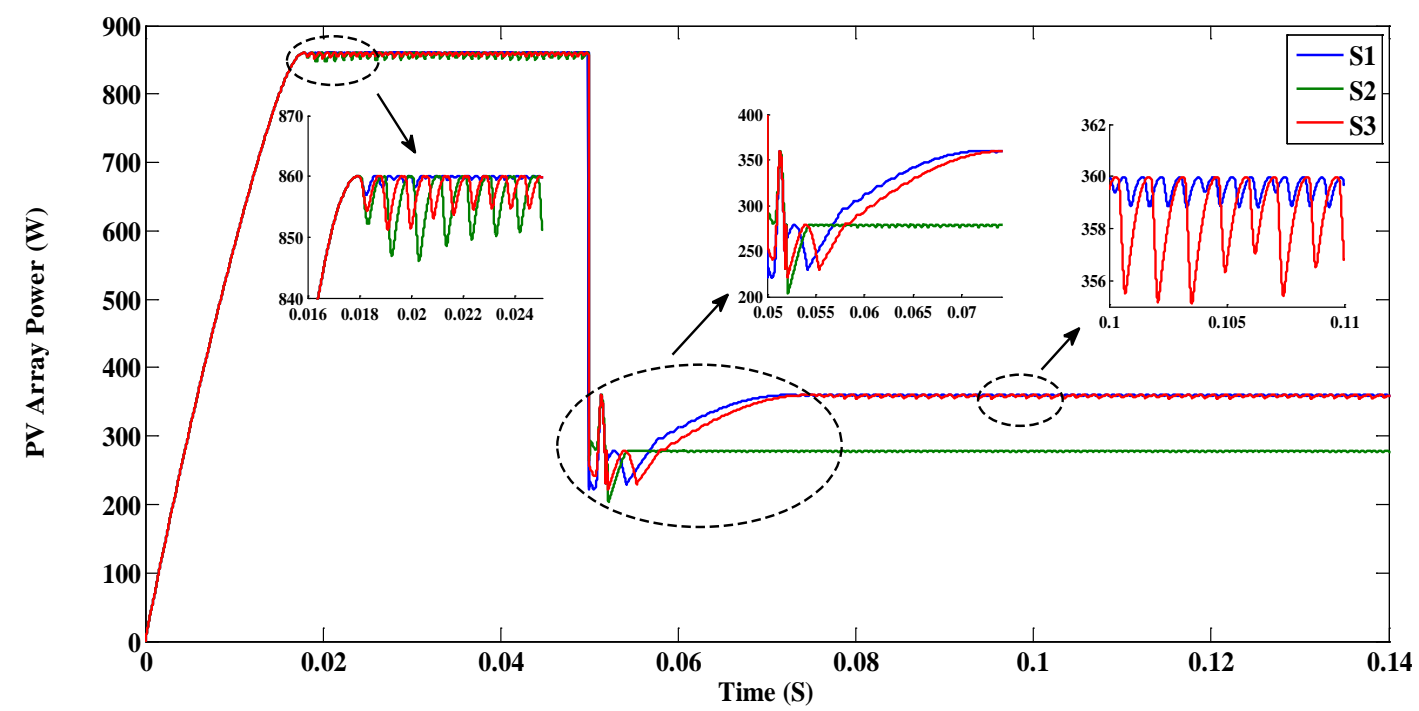

Figure 13. PV output powers for the scenario of Figure 12a.

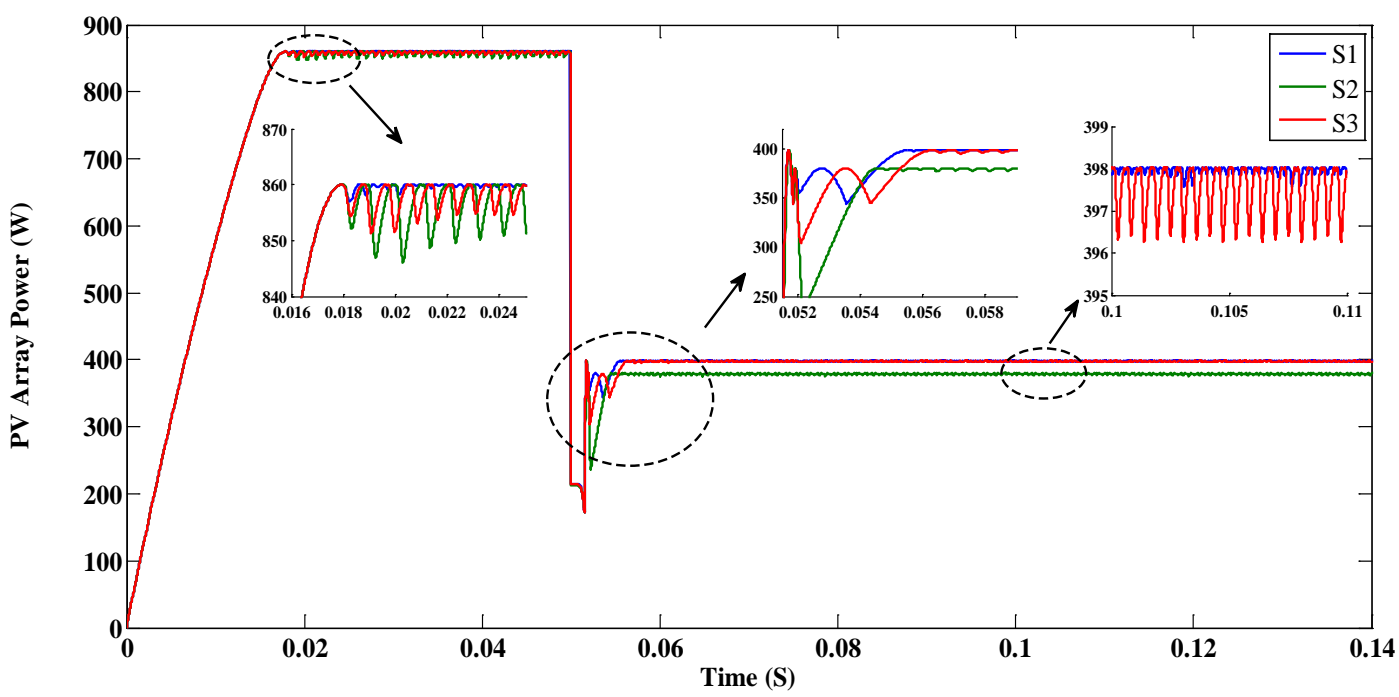

Figure 14. The PV output power for the scenario depicted in Figure 12b.

\section{Hardware Implementation}

The experimental setup for the proposed PV system has been developed as shown in Figure 15. To implement the proposed DSMPP algorithm, the digital signal processing (DSP) TMS320F28335 controller is used. The programmable solar array simulator power supply $62100 \mathrm{H}-600 \mathrm{~S}$ series is used to generate $I-V$ and $P-V$ curves under partial shaded conditions. This solar array simulator provides simulation of open-circuit voltage up to $1000 \mathrm{~V}$ and short-circuit current up to $25 \mathrm{~A}$. To further investigate the performance of the proposed DSMPP method in practice, three systems (S1, S2 and S3) are considered which are mentioned previously. To evaluate the operation of the proposed algorithm, different scenarios of shadowing are considered for experimental analysis. 
The scenario which is shown in Figure 16 is considered to investigate the effectiveness of the proposed method in reality which the experimental results for this scenario are shown in Figure 17. According to the linear function method [39] implemented in S2, under PSCs, the MPP related to the new reference voltage should be the GMPP; however, as shown in Figures 16b and 17, S2 fails to find the GMPP, and a LMPP with a value of $278.8 \mathrm{~W}$ is detected. For S1 and S3, where DSMPP and two-stage methods are implemented, respectively, the GMPP is obtained correctly. However, by comparing both, S1 can clearly find the GMPP in less time and the search time is significantly reduced where $\mathrm{T}_{\mathrm{GMPP}}$ for S1 and S3 are 22.64 and $24.68 \mathrm{~s}$, respectively. Moreover, the oscillation in power decreases significantly for S1 in which the oscillation values for S1 and S3 are 4.5 and 11.6 W,

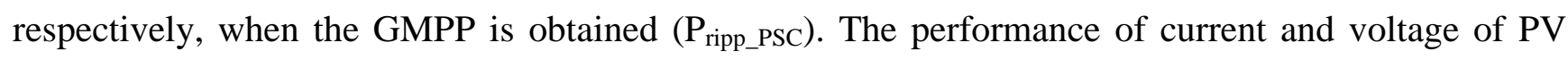
array for the scenario of Figure 16 for the proposed DSMPP algorithm is shown in Figure 18 which are from the time PS happens till when the GMPP is obtained.

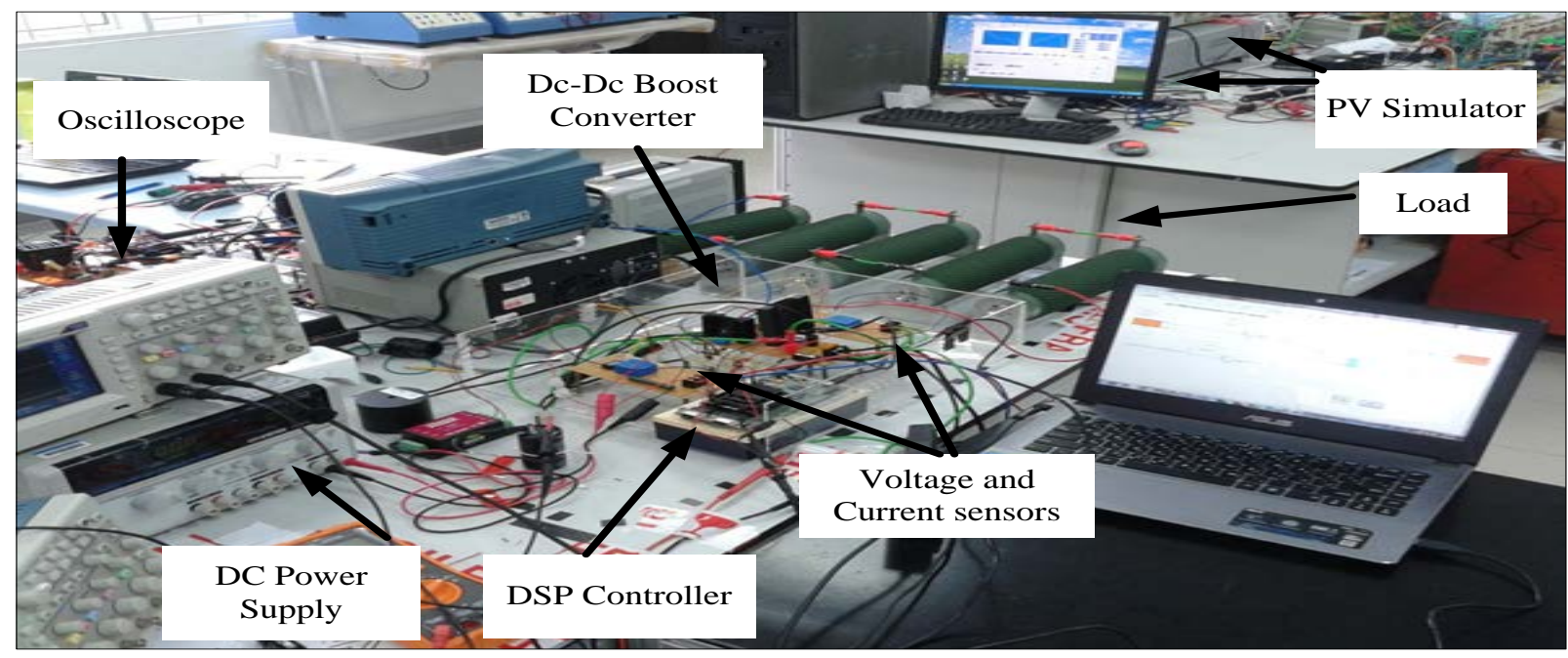

Figure 15. Experimental setup for proposed PV system.

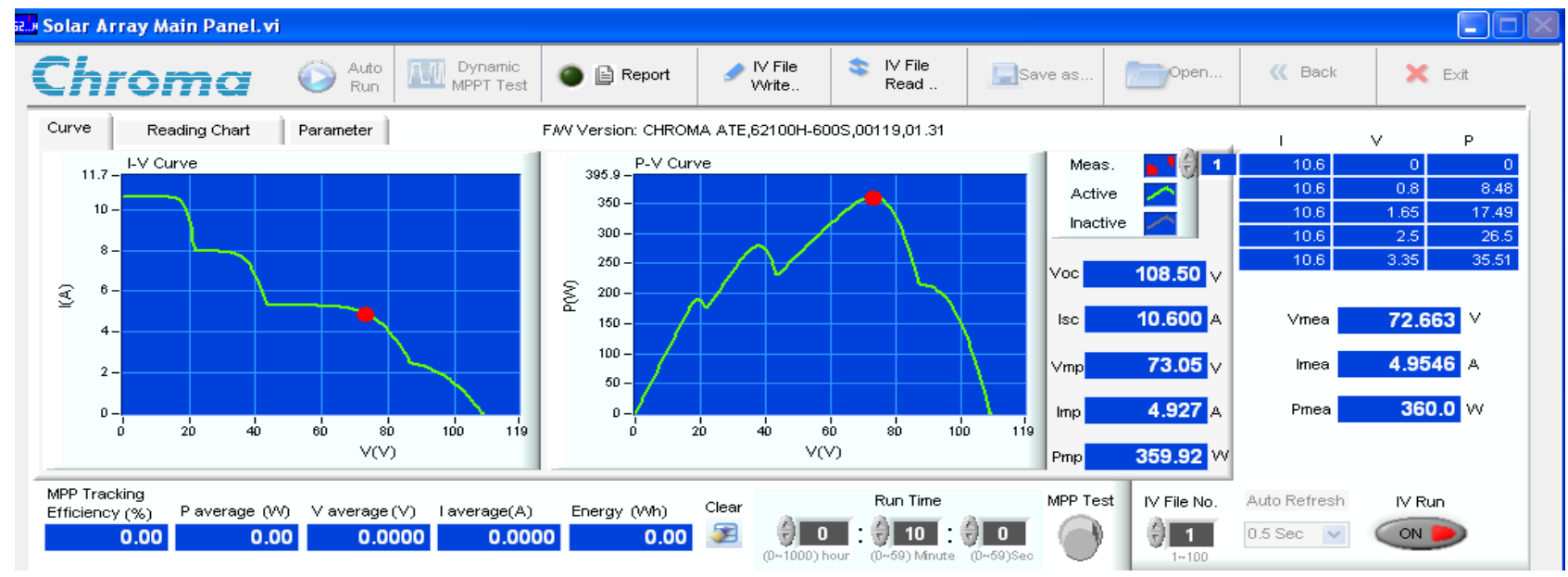

(a)

Figure 16. Cont. 


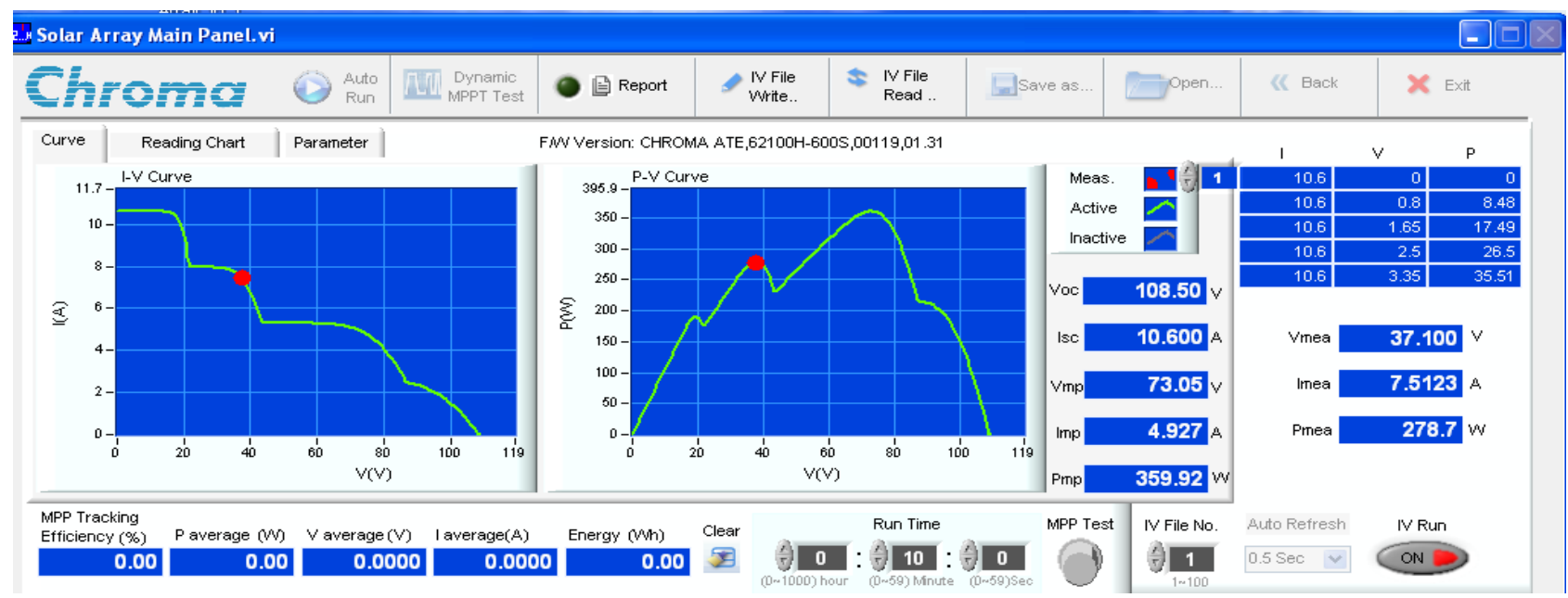

(b)

Figure 16. $P-V$ and $I-V$ curves under PSC (a) the detected GMPP by S1 and S3 and (b) The failed detected GMPP by $\mathrm{S} 2$.
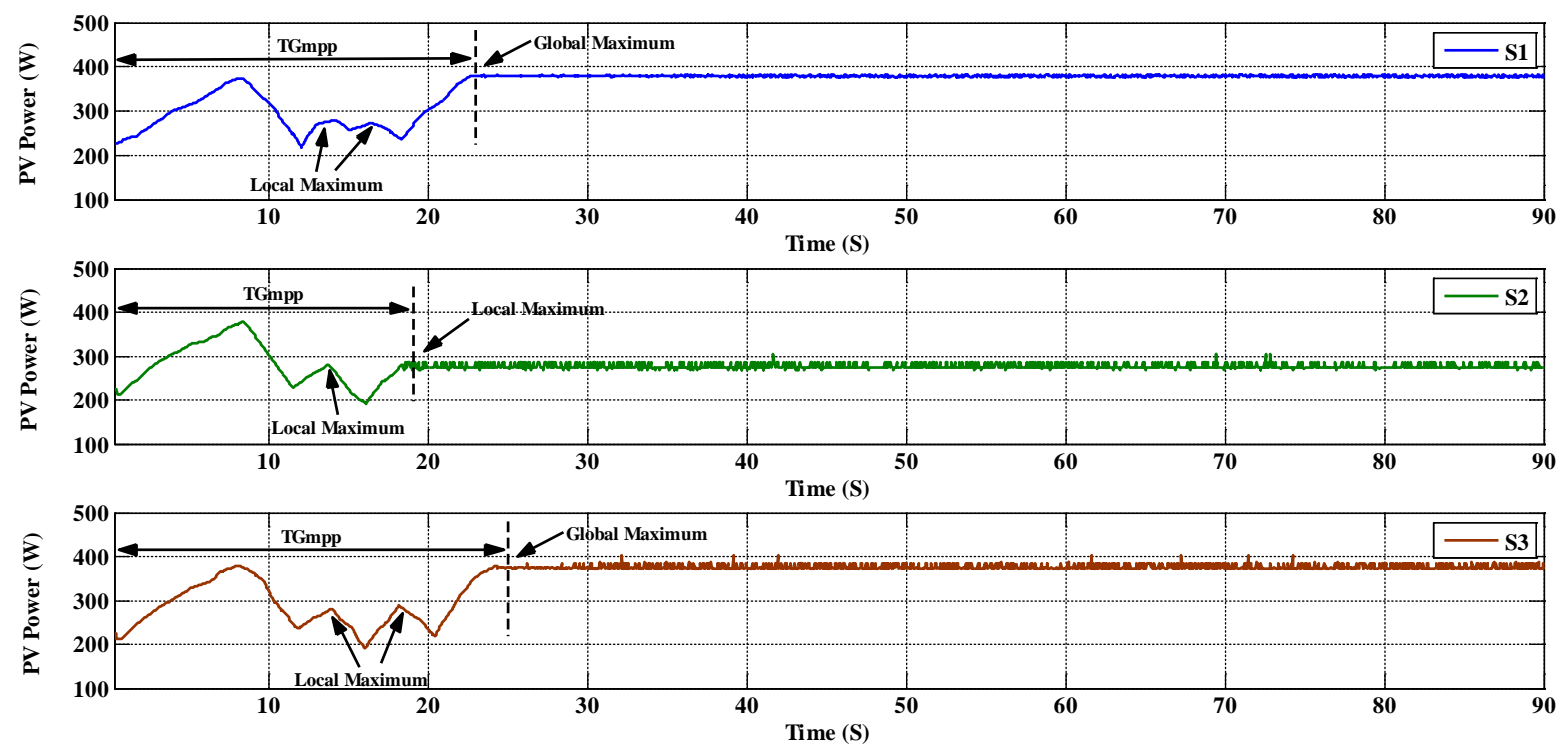

Figure 17. PV output power for the scenario of Figure 16.

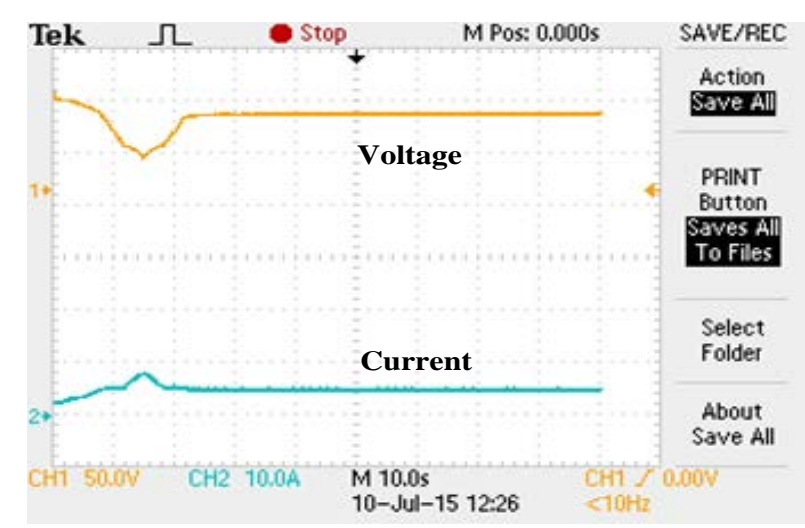

Figure 18. The performance of voltage and current for the scenarios of Figure 16 by implementing DSMPP method. 
The experimental results for the scenario depicted in Figure 19 are shown in Figure 20. As shown in Figures 19b and 20, again, S2 fails to find the GMPP, and only a LMPP with a value of $380.8 \mathrm{~W}$ is obtained. However, by using S1 and S3, the GMPP is obtained. Looking at both, the time required to reach the GMPP ( $\mathrm{T}_{\mathrm{GMPP}}$ ) for S1 (20.76 s) is less than S3 (24.08 s). In addition, the oscillation in power ( $\mathrm{P}_{\text {ripp_PSG }}$ ) of $\mathrm{S} 1$ is also less than S3 when the GMPP is obtained, with values of 3.8 and $9.6 \mathrm{~W}$, respectively. In Figure 21, the performance of voltage and current for the scenario of Figure 19 for the proposed DSMPP algorithm is shown.

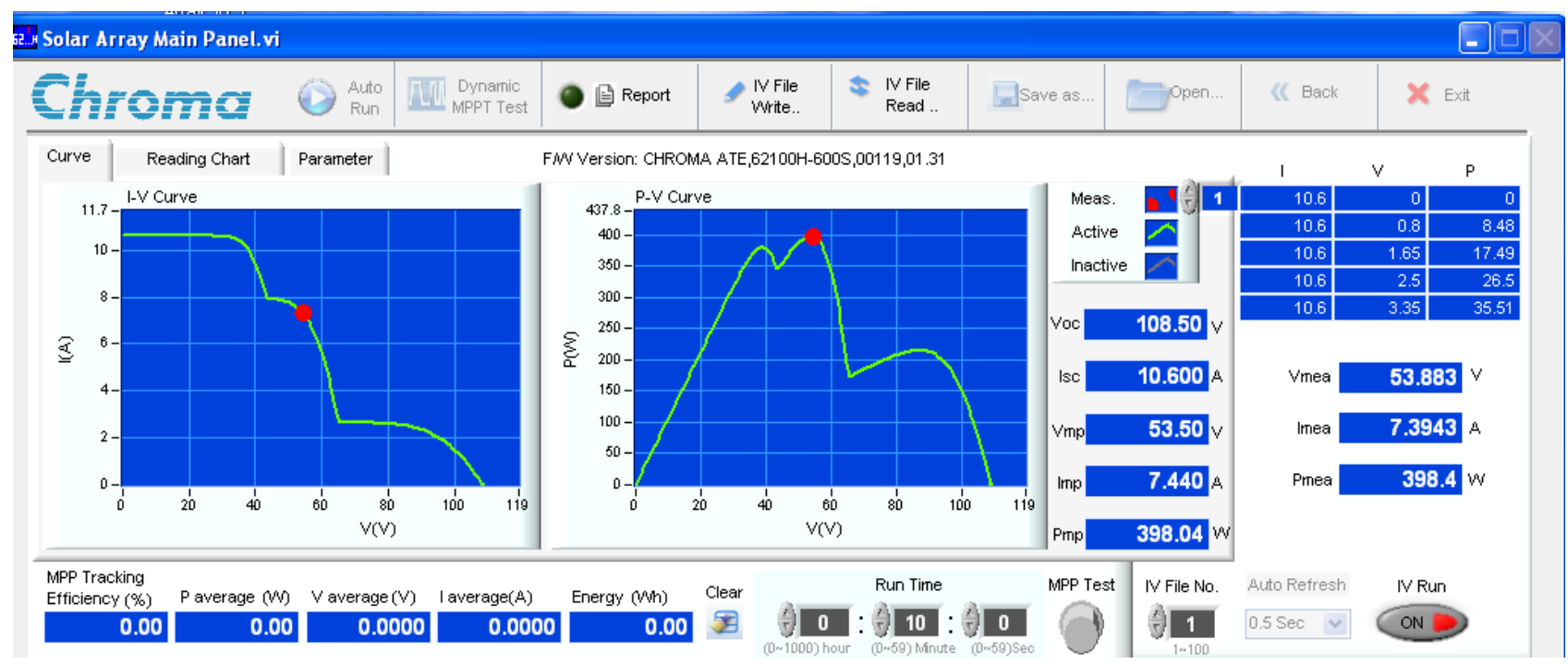

(a)

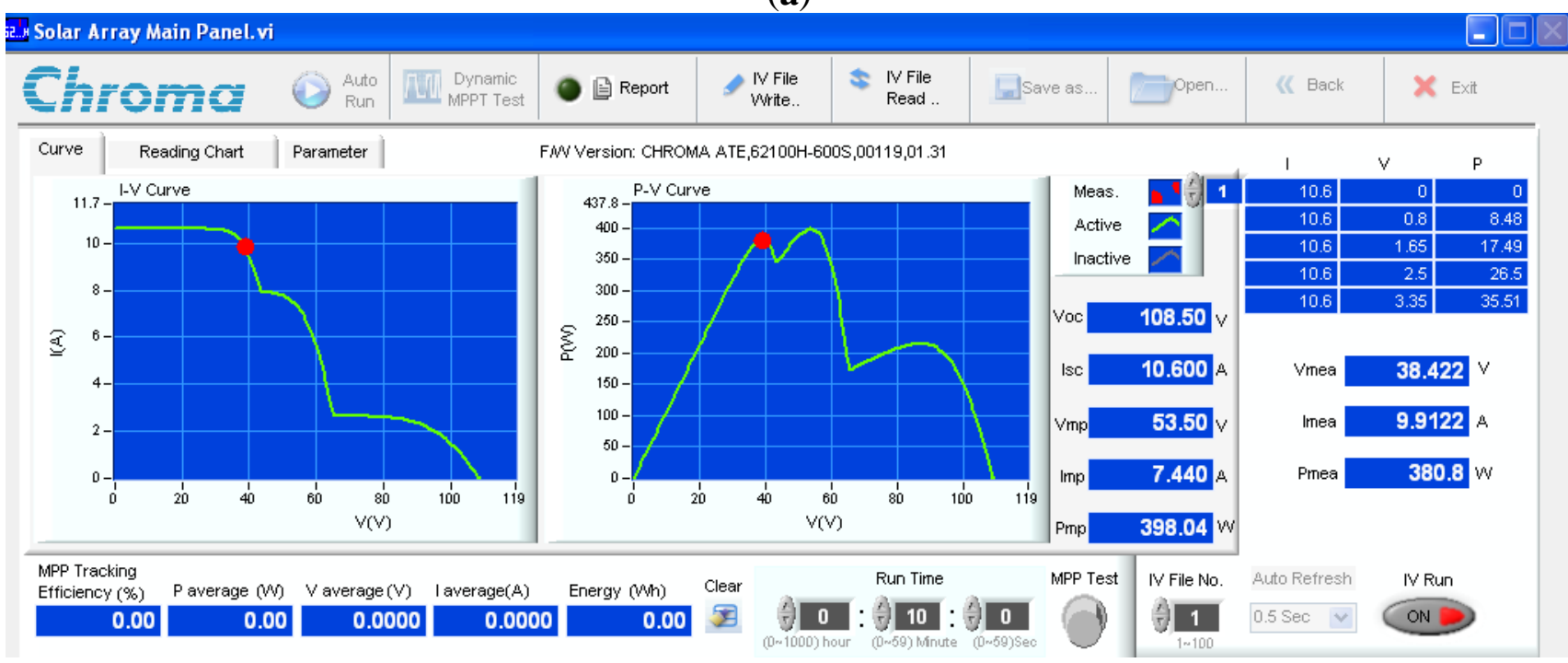

(b)

Figure 19. $P-V$ and $I-V$ curves under PSC (a) The detected GMPP by S1 and S3 and (b) The failed detected GMPP by S2 

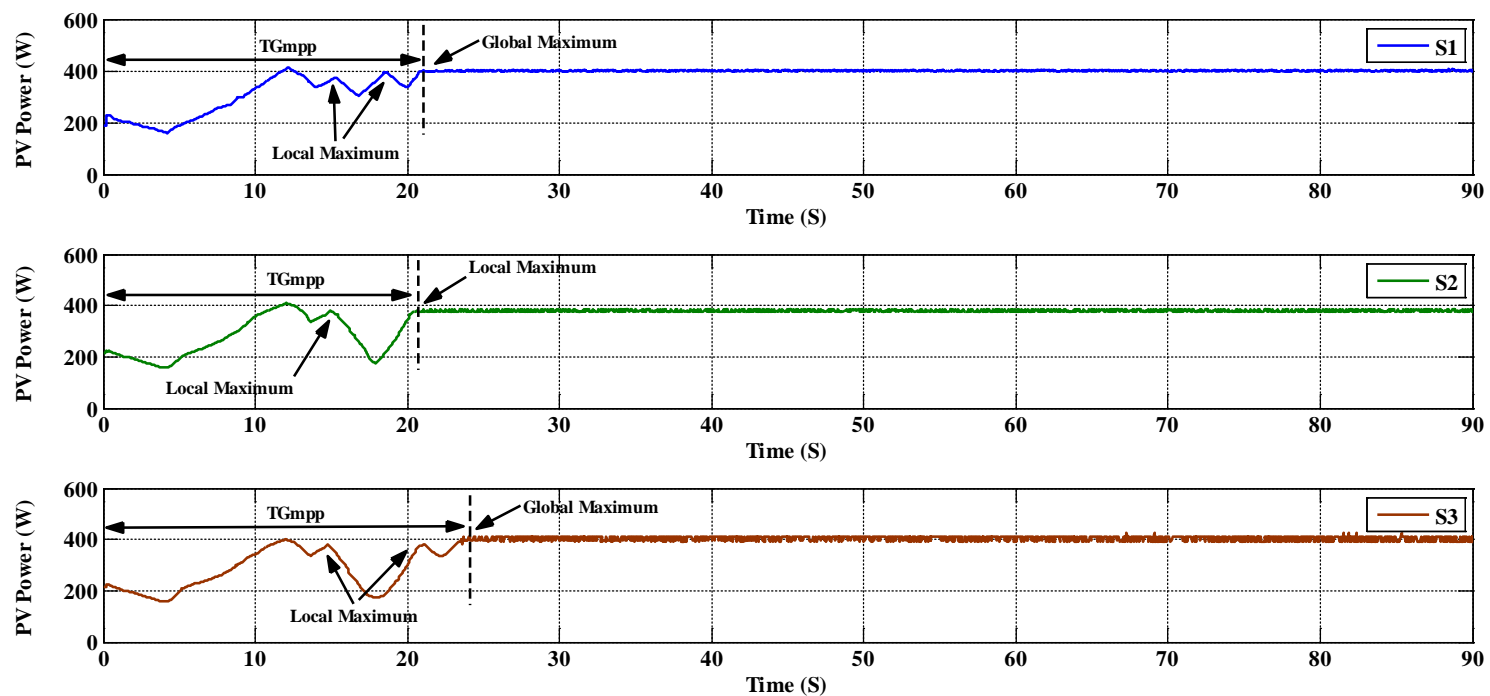

Figure 20. PV output power for the scenario of Figure 19.

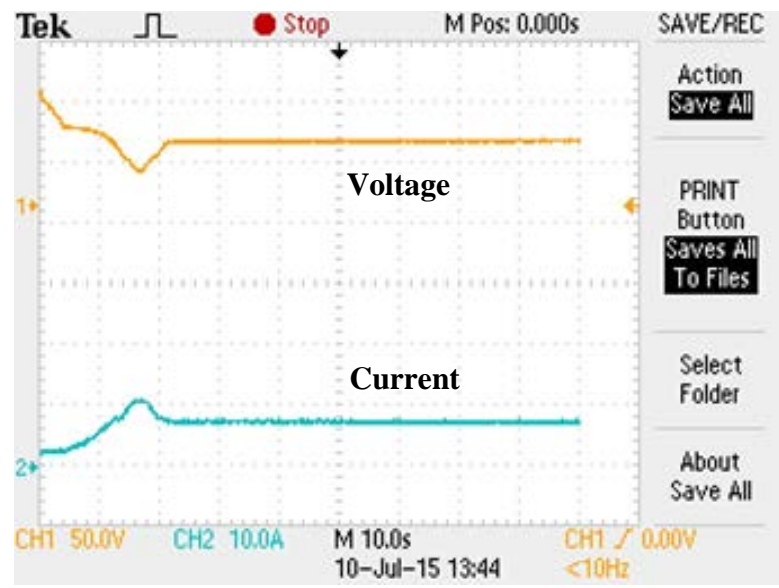

Figure 21. The performance of voltage and current for the scenarios of Figure 19 by implementing the DSMPP method.

The scenarios of shadowing which are shown in Figure 22 are considered to verify the operation of the proposed method. Figures 23 and 24 show the experimental results for the scenarios depicted in Figure 22a,b respectively. As shown in Figure 23, under PSCs, the GMPP can be found by S1, S2 and $\mathrm{S} 3$, but $\mathrm{S} 1$ can obtain the GMPP faster than S2 and S3. The times required to reach the GMPP ( $\left.\mathrm{T}_{\mathrm{GMPP}}\right)$ are approximately 5.2, 13.88 and 21.8 s for S1, S2 and S3, respectively. By using the modified P \& O method in S1, the oscillation in power is significantly reduced, as the values for S1, S2 and S3 at the GMPP (Pripp_Psc) are 4.5, 14.2 and $12.5 \mathrm{~W}$, respectively.

As shown in Figure 24, under PSCs, the GMPP can be found by S1, S2 and S3, but S1 can obtain the GMPP faster than S2 and S3 can; the times required to reach the GMPP ( $\left.\mathrm{T}_{\mathrm{GMPP}}\right)$ are approximately 15.72, 23.48 and 27.24 s for S1, S2 and S3, respectively. By using the modified P \& O method in S1, the oscillation in power is significantly reduced, as the values for S1, S2 and S3 at the GMPP ( $\mathrm{P}_{\text {ripp_PSC}}$ ) are 3.2, 10.3 and $11.1 \mathrm{~W}$, respectively. The performance of current and voltage of PV array for the scenarios of Figure 22a, and Figure 22b for the proposed DSMPP algorithm are shown in Figure 25 respectively, which are measured from the time PS happens till when the GMPP is obtained. 


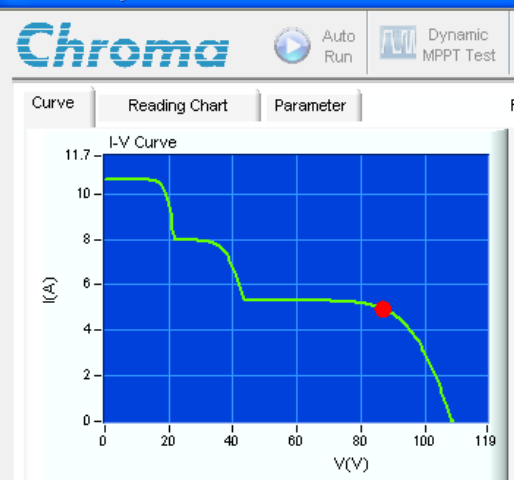

\begin{tabular}{|l|l|l}
\hline IV Report & $\begin{array}{l}\text { IV File } \\
\text { Write. }\end{array}$ & $\$ \begin{array}{l}\text { IV File } \\
\text { Read. }\end{array}$ \\
\hline
\end{tabular}

MPP Tracking
Efficiency $(\%) \quad P$ average $(M) \quad V$ average $(V)$ laverage(A) Energy (M) Clear $0.00 \quad 0.00 \quad 0.0000$ average $(M)$ average $(V)$ average( $A)$
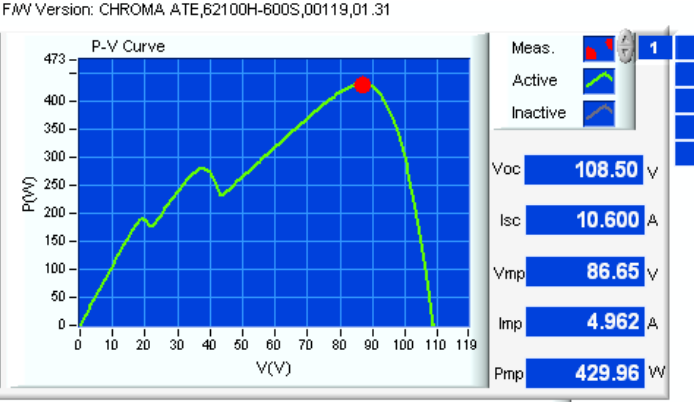

« Back $\quad \times$ Exit

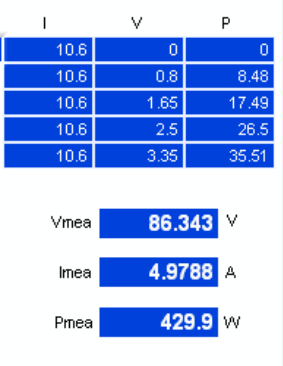

MPP Test IV Fiveris.

into Refresh IVRun

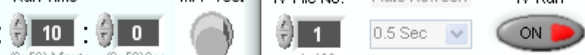

(a)

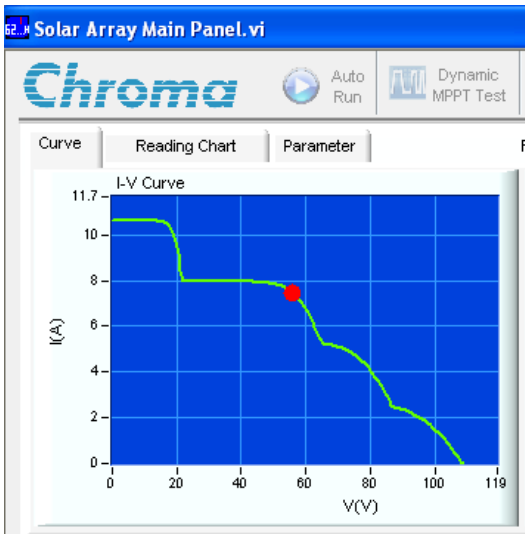

\begin{tabular}{|c|c|c|}
\hline - 圆 Report & $\begin{array}{l}\text { IV File } \\
\text { Witte.. }\end{array}$ & $\begin{array}{l}\text { IVFile } \\
\text { Read. }\end{array}$ \\
\hline
\end{tabular}

FMV Version: CHROMA, ATE, $62100 \mathrm{H}-600 \mathrm{~S}, 00119,01.31$
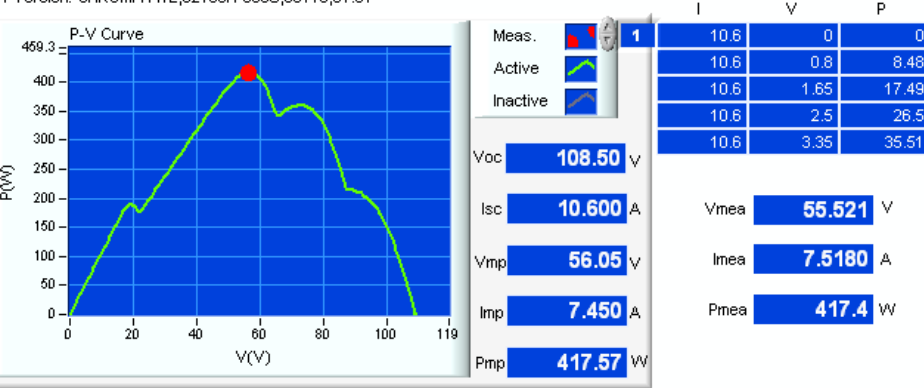

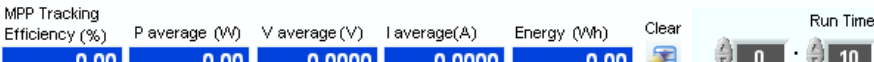
0.00

Figure 22. $P-V$ and $I-V$ curves for different scenarios of shading (a) the detected GMPP by S1, S2, and S3 and (b) the detected GMPP by S1, S2, and S3
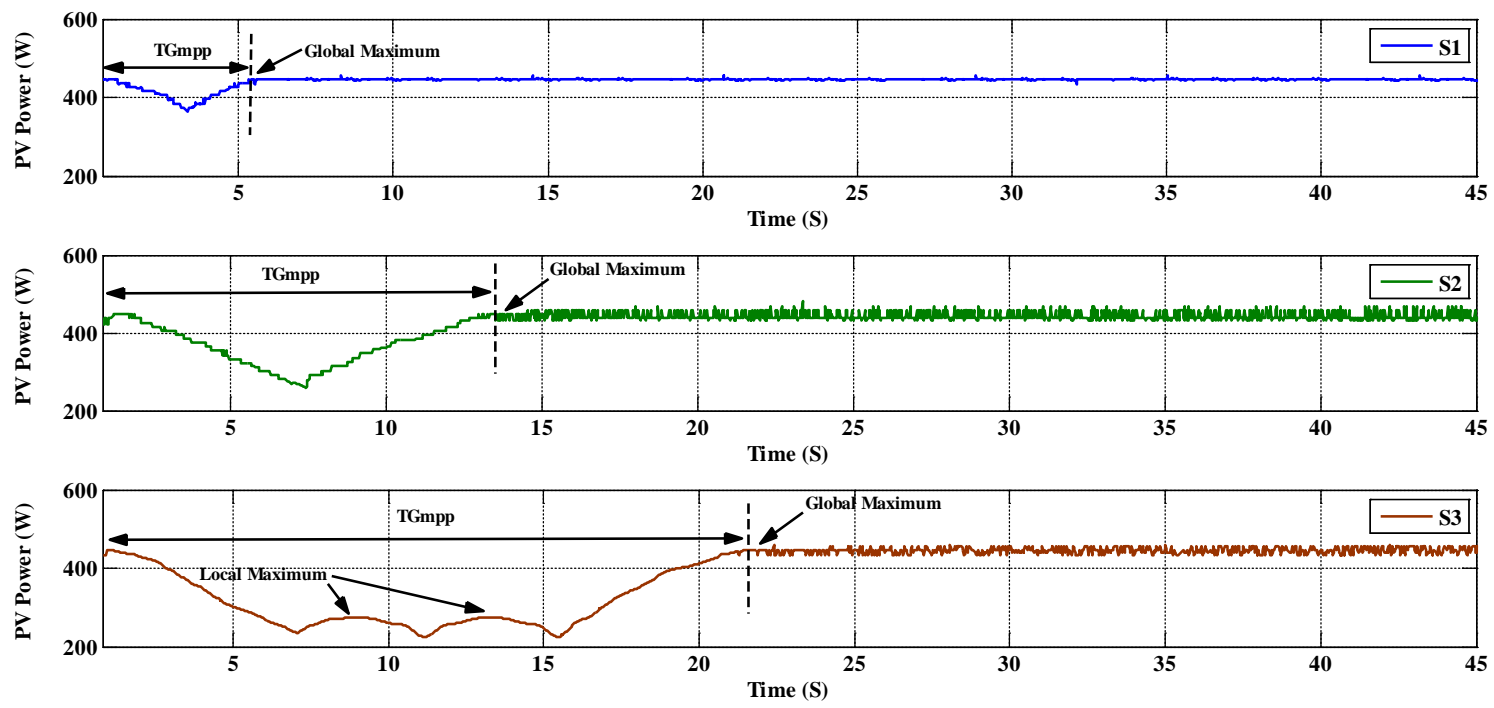

Figure 23. PV output power for the scenario of Figure 22a. 

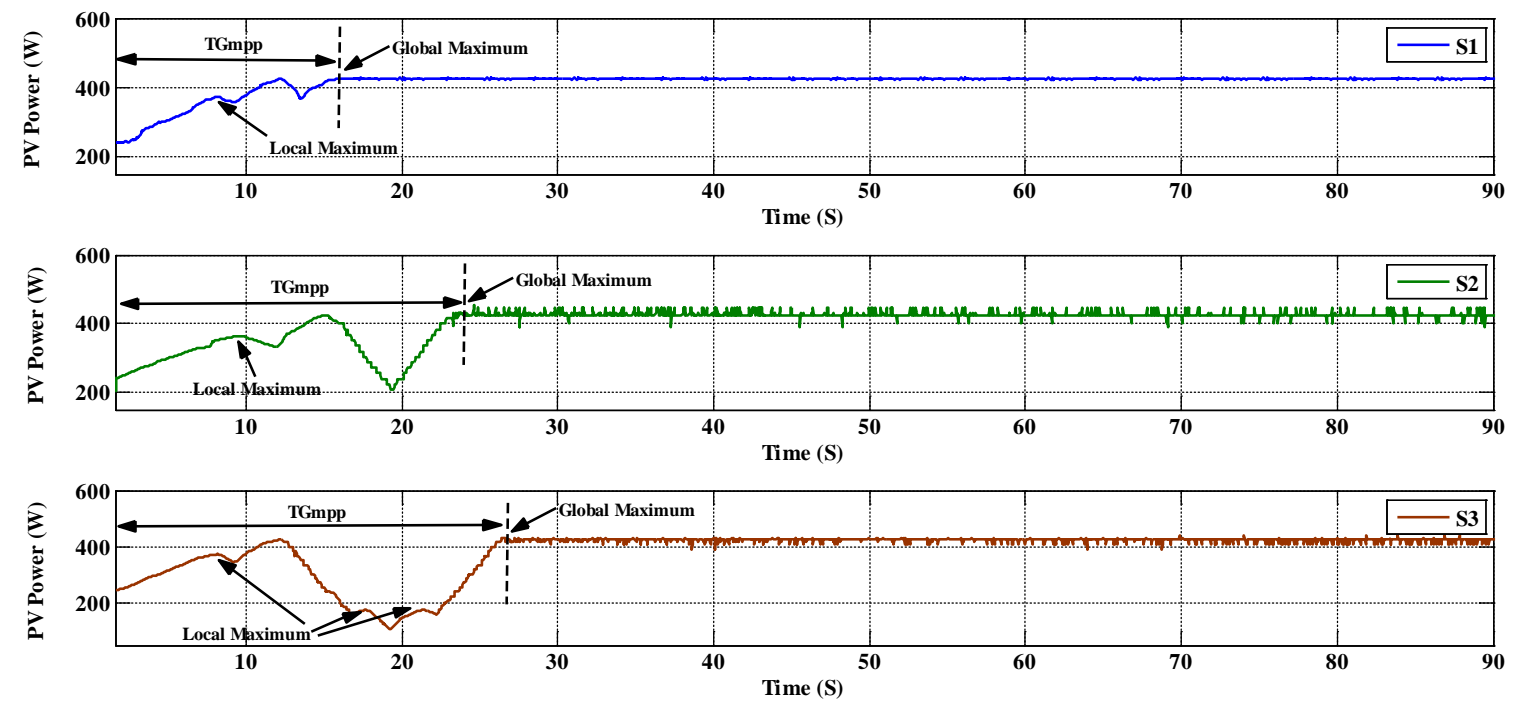

Figure 24. PV output power for the scenario of Figure 22b.

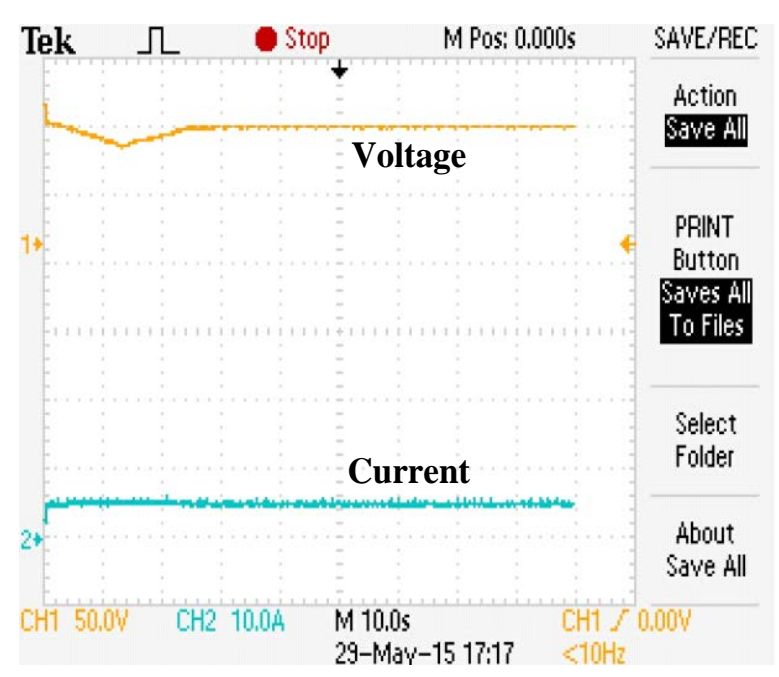

(a)

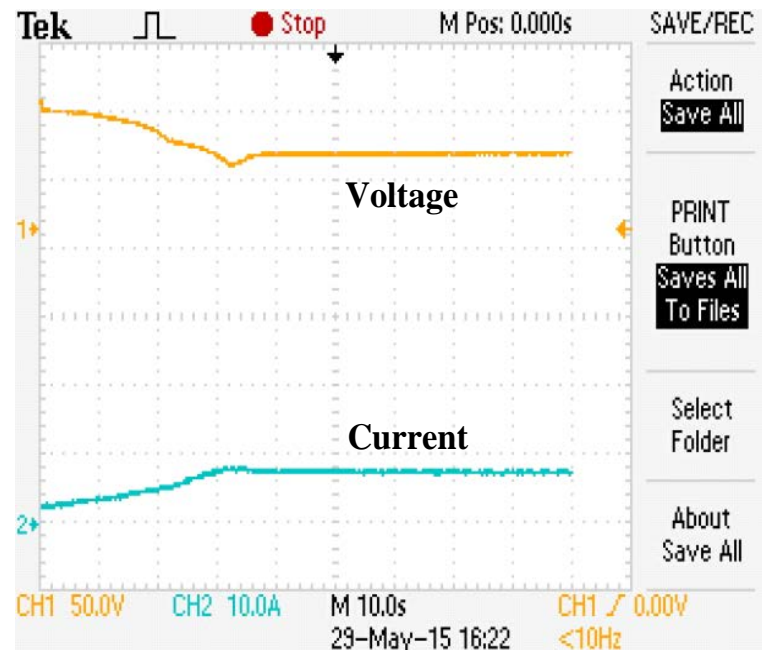

(b)

Figure 25. The performance of voltage and current for the scenarios of (a) Figure 22a and (b) Figure 22b by implementing the DSMPP method.

The scenario which is depicted in Figure 26 is considered for verifying the operation of the proposed method and the experimental result for this scenario is shown in Figure 27. As shown in Figure 27, for the considered scenario, the GMPP is obtained by S1, S2 and S3, but the time required to reach the GMPP ( $\mathrm{T}_{\mathrm{GMPP}}$ ) in S1 is less than that in S2 and S3: the times to reach the GMPP are almost 13.48, 25.48 and $31.4 \mathrm{~s}$ for S1, S2 and S3, respectively. Moreover, the oscillation in power for S2 and S3 is greater than that for S1; the GMPP values ( $\mathrm{P}_{\text {ripp_PSC }}$ ) are 2.8, 9.2 and 10.4 W for S1 S2 and S3, respectively. The performance of current and voltage of PV array for the scenarios of Figure 26 for the proposed DSMPP algorithm are shown in Figure 28 which are from the time PS happens till when the GMPP is obtained. In Table 4, the experimental results are summarized and the abbreviations are defined in Section 5. 


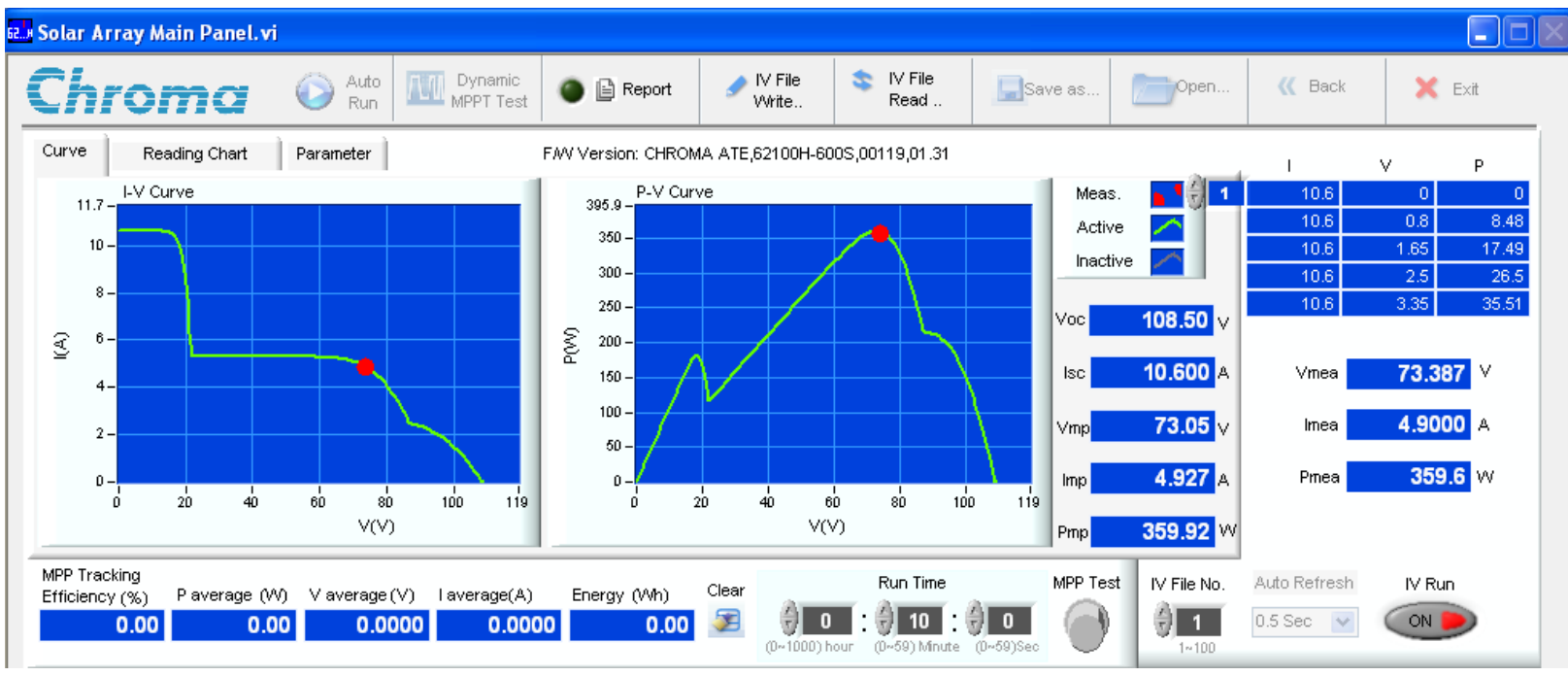

Figure 26. $P-V$ and $I-V$ curves under partial shading conditions.
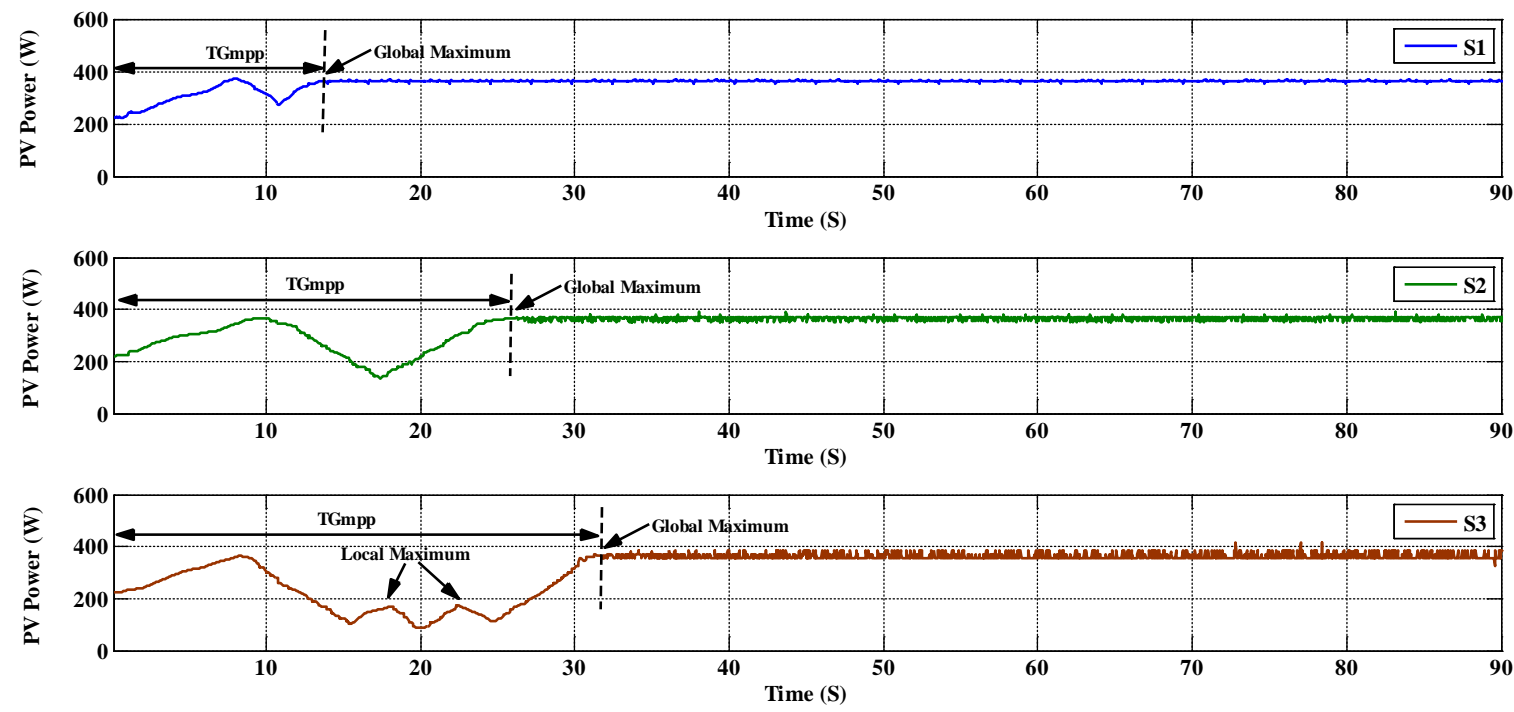

Figure 27. PV output power for the scenario of Figure 26.

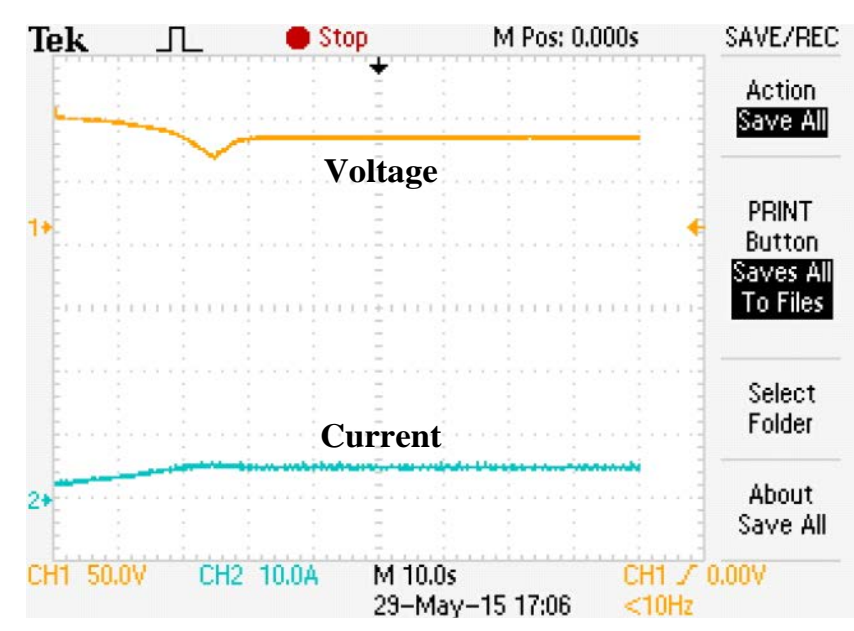

Figure 28. The performance of voltage and current for the scenarios of Figure 26 by implementing the DSMPP method. 
Table 4. The experimental results for S1, S2 and S3.

\begin{tabular}{cccccc}
\hline Items & Scenario & SOP & T $_{\text {GMPP }}$ & P $_{\text {ave_PSC }}$ & P $_{\text {ripp_PSC }}$ \\
\hline System & & & & & \\
S1 & 16 & Successful & 22.64 & 360 & 4.5 \\
S2 & 16 & Failed & - & 278.8 & - \\
S3 & 16 & Successful & 24.68 & 360 & 11.6 \\
S1 & 19 & Successful & 20.76 & 398.4 & 3.8 \\
S2 & 19 & Failed & - & 380.8 & - \\
S3 & 19 & Successful & 24.08 & 398.4 & 9.6 \\
S1 & $22 . \mathrm{a}$ & Successful & 5.2 & 429.9 & 4.5 \\
S2 & $22 . \mathrm{a}$ & Successful & 13.88 & 429.9 & 14.2 \\
S3 & $22 . \mathrm{a}$ & Successful & 21.8 & 429.9 & 12.5 \\
S1 & $22 . \mathrm{b}$ & Successful & 15.72 & 417.4 & 3.2 \\
S2 & $22 . \mathrm{b}$ & Successful & 23.48 & 417.4 & 10.3 \\
S3 & $22 . \mathrm{b}$ & Successful & 27.24 & 417.4 & 11.1 \\
S1 & 26 & Successful & 13.48 & 359.6 & 2.8 \\
S2 & 26 & Successful & 25.48 & 359.6 & 9.2 \\
S3 & 26 & Successful & 31.4 & 359.6 & 10.4 \\
\hline
\end{tabular}

\section{Conclusions}

Under PSCs in which multiple peak power points exist in the $P-V$ curve of a PV array, conventional methods cannot detect the GMPP. In recent years, researchers have developed different techniques to obtain the GMPP, but each of the techniques has drawbacks. This paper successfully demonstrated a novel DSMPP algorithm for tracking the GMPP under PSCs. In this method, mathematical analysis is performed to estimate the location of possible GMPPs; based on this analysis, the search zone is identified, and simultaneously, the possible MPPs that lead to determining the GMPP in the minimum time are specified. The proposed method is not limited to specific shapes of $P-V$ curves and can track the GMPP under all changing climate conditions with high accuracy. In this work, the P \& O method based on duty cycle adjustment is used, which is modified to increase the speed of the search and also to reduce the oscillation. By using the modified P \& O method, the PID controller is no longer required, which leads to a decrease in the complexity of the PV system and eliminates certain transient behaviors, such as oscillation and overshoots. Therefore, based on the analytical, simulations and practical results, it is concluded that the proposed algorithm can obtain the MPP under PSCs in the minimum amount of time with the highest accuracy and the minimum oscillations in power, which leads to achieve the maximum available energy. This method is not limited to specific scenario of shadowing and is able to track GMPP under various climate conditions.

\section{Acknowledgments}

This work is supported by the Fundamental Research Gant Scheme under the Ministry of Education, Malaysia (03-01-14-1413FR). 


\section{Author Contributions}

Shahrooz Hajighorbani designed and developed the main parts of the research work, including simulation model, experimental set up, and analyses of the obtained results. Shahrooz Hajighorbani was also mainly responsible for preparing the paper. Mohd Amran Mohd Radzi contributed in simulation, experimental, and writing parts. Mohd Zainal Abidin Ab Kadir and Suhaidi Shafie also involved in verifying the work and actively contributed to finalize the manuscript.

\section{Conflicts of Interest}

The authors declare no potential conflict of interest.

\section{References}

1. Tomabechi, K. Energy resources in the future. Energies 2010, 3, 686-695.

2. Liu, G.; Nguang, S.K.; Partridge, A. A general modeling method for I-V characteristics of geometrically and electrically configured photovoltaic arrays. Energy Convers. Manag. 2011, 52, 3439-3445.

3. Shirzadi, S.; Hizam, H.; Wahab, N.I.A. Mismatch losses minimization in photovoltaic arrays by arranging modules applying a genetic algorithm. Sol. Energy 2014, 108, 467-478.

4. Elminir, H.K.; Ghitas, A.E.; Hamid, R.; El-Hussainy, F.; Beheary, M.; Abdel-Moneim, K.M. Effect of dust on the transparent cover of solar collectors. Energy Convers. Manag. 2006, 47, 3192-3203.

5. Ishaque, K.; Salam, Z. A review of maximum power point tracking techniques of PV system for uniform insolation and partial shading condition. Renew. Sustain. Energy Rev. 2013, 19, 475-488.

6. Piegari, L.; Rizzo, R.; Spina, I.; Tricoli, P. Optimized adaptive perturb and observe maximum power point tracking control for photovoltaic generation. Energies 2015, 8, 3418-3436.

7. Lee, J.-S.; Lee, K.B. Variable dc-link voltage algorithm with a wide range of maximum power point tracking for a two-string PV system. Energies 2013, 6, 58-78.

8. Yau, H.-T.; Wu, C.-H. Comparison of extremum-seeking control techniques for maximum power point tracking in photovoltaic systems. Energies 2011, 4, 2180-2195.

9. Sera, D.; Kerekes, T.; Teodorescu, R.; Blaabjerg, F. Improved MPPT algorithms for rapidly changing environmental conditions. In Proceedings of the 12th International Power Electronics and Motion Control Conference (EPE-PEMC), Portoroz, Slovenia, 30 August-1 September 2006; pp. 1614-1619.

10. Pilawa-Podgurski, R.C.; Perreault, D.J. Submodule integrated distributed maximum power point tracking for solar photovoltaic applications. IEEE Trans. Power Electron. 2013, 28, 2957-2967.

11. Boztepe, M.; Guinjoan, F.; Velasco-Quesada, G.; Silvestre, S.; Chouder, A.; Karatepe, E. Global MPPT scheme for photovoltaic string inverters based on restricted voltage window search algorithm. IEEE Trans. Ind. Electron. 2014, 61, 3302-3312.

12. Bazzi, A.M.; Krein, P.T. Ripple correlation control: an extremum seeking control perspective for real-time optimization. IEEE Trans. Power Electron. 2014, 29, 988-995.

13. Shiau, J.-K.; Wei, Y.-C.; Lee, M.-Y. Fuzzy controller for a voltage-regulated solar-powered MPPT system for hybrid power system applications. Energies 2015, 8, 3292-3312. 
14. El Khateb, A.H.; Rahim, N.A.; Selvaraj, J. Fuzzy logic control approach of a maximum power point employing SEPIC converter for standalone photovoltaic system. Procedia Environ. Sci. 2013, 17, 529-536.

15. Hajighorbani, S.; Radzi, M.; Kadir, M.A.; Shafie, S.; Khanaki, R.; Maghami, M. Evaluation of fuzzy logic subsets effects on maximum power point tracking for photovoltaic system. Int. J. Photoenergy 2014, 2014, 719126.

16. Guenounou, O.; Dahhou, B.; Chabour, F. Adaptive fuzzy controller based MPPT for photovoltaic systems. Energy Convers. Manag. 2014, 78, 843-850.

17. Liu, C.-L.; Chen, J.-H.; Liu, Y.-H.; Yang, Z.-Z. An asymmetrical fuzzy-logic-control-based MPPT algorithm for photovoltaic systems. Energies 2014, 7, 2177-2193.

18. Hiyama, T.; Kitabayashi, K. Neural network based estimation of maximum power generation from PV module using environmental information. IEEE Trans. Energy Convers. 1997, 12, 241-247.

19. Muthuramalingam, M.; Manoharan, P. Comparative analysis of distributed MPPT controllers for partially shaded stand alone photovoltaic systems. Energy Convers. Manag. 2014, 86, 286-299.

20. Chowdhury, S.R.; Saha, H. Maximum power point tracking of partially shaded solar photovoltaic arrays. Sol. Energy Mater. Sol. Cells 2010, 94, 1441-1447.

21. Jiang, L.L.; Maskell, D.L.; Patra, J.C. A novel ant colony optimization-based maximum power point tracking for photovoltaic systems under partially shaded conditions. Energy Build. 2013, 58, 227-236.

22. Shaiek, Y.; Smida, M.B.; Sakly, A.; Mimouni, M.F. Comparison between conventional methods and GA approach for maximum power point tracking of shaded solar PV generators. Sol. Energy 2013, 90, 107-122.

23. Sarvi, M.; Ahmadi, S.; Abdi, S. A PSO-based maximum power point tracking for photovoltaic systems under environmental and partially shaded conditions. Prog. Photovolt. Res. Appl. 2015, 23, 201-214.

24. Zbeeb, A.; Devabhaktuni, V.; Sebak, A.R. Improved photovoltaic MPPT algorithm adapted for unstable atmospheric conditions and partial shading. In Proceedings of the 2009 International Conference on Clean Electrical Power, Capri, Italy, 9-11 June 2009; pp. 320-323.

25. Levron, Y.; Shmilovitz, D. Maximum power point tracking employing sliding mode control. IEEE Trans. Circuits Syst. I Regul. Papers 2013, 60, 724-732.

26. Cabal, C.; Martínez-Salamero, L.; Séguier, L.; Alonso, C.; Guinjoan, F. Maximum power point tracking based on sliding-mode control for output-series connected converters in photovoltaic systems. IET Power Electron. 2013, 7, 914-923.

27. Ishaque, K.; Salam, Z.; Taheri, H.; Shamsudin, A. maximum power point tracking for PV System under partial shading condition via particle swarm optimization. In Proceedings of the IEEE Applied Power Electronics Colloquium (IAPEC), Johor Bahru, Malaysia, 18-19 April 2011.

28. Tsai, M.-F.; Tseng, C.-S.; Hong, G.-D.; Lin, S.-H. A novel MPPT control design for PV modules using neural network compensator. In Proceedings of the 2012 IEEE International Symposium on Industrial Electronics (ISIE), Hangzhou, China, 28-31 May 2012; pp. 1742-1747. 
29. Jiang, L.L.; Nayanasiri, D.; Maskell, D.L.; Vilathgamuwa, D. A Simple and efficient hybrid maximum power point tracking method for PV systems under partially shaded condition. In Proceedings of the IECON 39th Annual Conference of the IEEE Industrial Electronics Society, Vienna, Austria, 10-13 November 2013; pp. 1513-1518.

30. Lian, K.; Jhang, J.; Tian, I. A maximum power point tracking method based on perturb-and-observe combined with particle swarm optimization. IEEE J. Photovolt. 2014, 4, 626-633.

31. Kobayashi, K.; Takano, I.; Sawada, Y. A study of a two stage maximum power point tracking control of a photovoltaic system under partially shaded insolation conditions. Sol. Energy Mater. Sol. Cells 2006, 90, 2975-2988.

32. Nguyen, D.; Lehman, B. An adaptive solar photovoltaic array using model-based reconfiguration algorithm. IEEE Trans. Ind. Electron. 2008, 55, 2644-2654.

33. Patel, H.; Agarwal, V. Maximum power point tracking scheme for PV systems operating under partially shaded conditions. IEEE Trans. Ind. Electron. 2008, 55, 1689-1698.

34. Bayod-Rújula, Á.-A.; Cebollero-Abián, J.-A. A novel MPPT method for PV systems with irradiance measurement. Sol. Energy 2014, 109, 95-104.

35. Radjai, T.; Rahmani, L.; Mekhilef, S.; Gaubert, J.P. Implementation of a modified incremental conductance MPPT algorithm with direct control based on a fuzzy duty cycle change estimator using Dspace. Sol. Energy 2014, 110, 325-337.

36. Al-Diab, A.; Sourkounis, C. Variable Step Size P \& O MPPT algorithm for PV systems. In Proceedings of the 12th International Conference on Optimization of Electrical and Electronic Equipment (OPTIM), Bochum, Germany, 20-22 May 2010; pp. 1097-1102.

37. Mellit, A.; Rezzouk, H.; Messai, A.; Medjahed, B. FPGA-based real time implementation of MPPT-controller for photovoltaic systems. Renew. Energy 2011, 36, 1652-1661.

38. Yang, Y.; Zhao, F.P. Adaptive perturb and observe MPPT technique for grid-connected photovoltaic inverters. Procedia Eng. 2011, 23, 468-473.

39. Ji, Y.-H.; Jung, D.-Y.; Kim, J.-G.; Kim, J.-H.; Lee, T.-W.; Won, C.-Y. A real maximum power point tracking method for mismatching compensation in PV array under partially shaded conditions. IEEE Trans. Power Electron. 2011, 26, 1001-1009.

40. Woyte, A.; Nijs, J.; Belmans, R. Partial shadowing of photovoltaic arrays with different system configurations: Literature review and field test results. Sol. Energy 2003, 74, 217-233.

41. Ji, Y.-H.; Kim, J.-G.; Park, S.-H.; Kim, J.-H.; Won, C.-Y. C-language based PV array simulation technique considering effects of partial shading. In Proceedings of the IEEE International Conference on Industrial Technology, Gippsland, Australia, 10-13 February 2009; pp. 1-6.

42. Gokmen, N.; Karatepe, E.; Ugranli, F.; Silvestre, S. Voltage band based global MPPT controller for photovoltaic systems. Sol. Energy 2013, 98, 322-334.

43. Erickson, R.W.; Maksimovic, D. Fundamentals of Power Electronics; Springer-Verlag: Berlin, Germany, 2001.

44. El Ela, M.A.; Roger, J. Optimization of the function of a photovoltaic array using a feedback control system. Sol. Cells 1984, 13, 107-119.

45. Salas, V.; Olias, E.; Barrado, A.; Lazaro, A. Review of the maximum power point tracking algorithms for stand-alone photovoltaic systems. Sol. Energy Mater. Sol. Cells 2006, 90, 1555-1578. 
46. Oshiro, Y.; Ono, H.; Urasaki, N. A MPPT Control method for stand-alone photovoltaic system in consideration of partial shadow. In Proceedings of the 2011 IEEE Ninth International Conference on Power Electronics and Drive Systems (PEDS), Singapore, 5-8 December 2011; pp. 1010-1014.

47. Skoplaki, E.; Palyvos, J. On the temperature dependence of photovoltaic module electrical performance: A review of efficiency/power correlations. Sol. Energy 2009, 83, 614-624.

48. Kroposki, B.; Myers, D.; Emery, K.; Mrig, L.; Whitaker, C.; Newmiller, J. Photovoltaic module energy rating methodology development. In Proceedings of the Conference Record of the 25th IEEE Photovoltaic Specialists Conference, Washington, DC, USA, 13-17 May 1996.

(C) 2015 by the authors; licensee MDPI, Basel, Switzerland. This article is an open access article distributed under the terms and conditions of the Creative Commons Attribution license (http://creativecommons.org/licenses/by/4.0/). 